\title{
Expression of the Lhx genes apterous and lim 1 in an errant polychaete: implications for bilaterian appendage evolution, neural development, and muscle diversification
}

Christopher J Winchell ${ }^{1,2}$ and David K Jacobs ${ }^{1^{*}}$

\begin{abstract}
Background: Arthropod and vertebrate appendages appear to have evolved via parallel co-option of a plesiomorphic gene regulatory network. Our previous work implies that annelids evolved unrelated appendage-forming mechanisms; we therefore found no support for homology of parapodia and arthropodia at the level of the whole appendage. We expand on that study here by asking whether expression of the LIM homeobox (Lhx) genes apterous and lim1 in the annelid Neanthes arenaceodentata supports homology of the dorsal branches as well as the proximodistal axes of parapodia and arthropodia. In addition, we explore whether the neural expression of apterous and lim 1 in Neanthes supports the putative ancestral function of the Lhx gene family in regulating the differentiation and maintenance of neuronal subtypes.
\end{abstract}

Results: Both genes exhibit continuous expression in specific portions of the developing central nervous system, from hatching to at least the 13-chaetiger stage. For example, nerve cord expression occurs in segmentally iterated patterns consisting of diffuse sets of many lim 1-positive cells and comparatively fewer, clustered pairs of apterouspositive cells. Additionally, continuous apterous expression is observed in presumed neurosecretory ganglia of the posterior brain, while $\lim 1$ is continuously expressed in stomatogastric ganglia of the anterior brain. apterous is also expressed in the jaw sacs, dorsal parapodial muscles, and a presumed pair of cephalic sensory organs, whereas lim 1 is expressed in multiple pharyngeal ganglia, the segmental peripheral nervous system, neuropodial chaetal sac muscles, and parapodial ligules.

Conclusions: The early and persistent nervous system expression of apterous and lim 1 in Neanthes juveniles supports conservation of Lhx function in bilaterian neural differentiation and maintenance. Our results also suggest that diversification of parapodial muscle precursors involves a complementary LIM code similar to those generating distinct neuronal identities in fly and mouse nerve cords. Expression of apterous and lim 1 in discrete components of developing parapodia is intriguing but does not map to comparable expression of these genes in developing arthropod appendages. Thus, annelid and arthropod appendage development apparently evolved, in part, via distinct co-option of the neuronal regulatory architecture. These divergent patterns of apterous and $\lim 1$ activity seemingly reflect de novo origins of parapodia and arthropodia, although we discuss alternative hypotheses.

\footnotetext{
* Correspondence: Email: djacobs@ucla.edu

'Department of Ecology and Evolutionary Biology, University of California, Los Angeles, 621 Charles E Young Drive South, Los Angeles CA 90095-1606, USA

Full list of author information is available at the end of the article
} 


\section{Background}

Annelid parapodia and arthropod legs (arthropodia) are well-known types of protostome appendages. Under the Articulata hypothesis, which posits an annelid-arthropod sister relationship, parapodia and arthropodia are often considered homologous [1]. However, favor for this notion has waned considerably since the late 1990s [2,3], as new types of phylogenetic data and new views of animal relationships have become established (see [4] for a recent review). Despite the firm molecular-phylogenetic separation of annelids from arthropods, and the paucity of morphologic details to homologize their appendages, the evolutionary relationship between parapodia and arthropodia is still a contentious issue, with some authors strongly favoring (for example, [5]), guardedly favoring, (for example, [6]), or contradicting (for example, [7]) homology.

Previously, we addressed this controversy from a developmental-genetic perspective by analyzing the expression of Distal-less, dachshund, and optomotor blind (three arthropod/vertebrate appendage genes) in the parapodiabearing polychaete Neanthes arenaceodentata [8]. Finding no compelling evidence of shared developmental mechanisms of appendage formation, we concluded that parapodia evolved independently of arthropodia and vertebrate limbs. These previous results are intriguing because similar mechanisms do control certain aspects of arthropod and vertebrate appendage development [9-11], suggesting that a primitive regulatory network (present in the protostomedeuterostome ancestor) underwent parallel recruitment to appendage-forming roles in arthropods and vertebrates, but not in annelids. We revisit this issue in the current paper by examining whether the expression of two additional Neanthes genes, orthologs of the LIM homeobox (Lhx) genes apterous ( $a p)$ and lim1, provide evidence for or against homology of particular architectural features of annelid and arthropod appendages.

In diverse arthropods, expression patterns of ap and the POU homeobox gene $p d m$ suggest that a common ancestor bore branched limbs with distinct dorsal and ventral elements. In crustaceans, for example, $a p$ and $p d m$ are expressed throughout the developing gill-like epipods that branch dorsally from the limbs $[12,13]$. Evidence from the fruit fly Drosophila melanogaster suggests that insect wings are also akin to dorsal elements of branched limbs, as they originate from common embryonic primordia shared with legs [14,15], and indeed, $a p$ and $p d m$ are expressed in developing Drosophila wings, where ap specifies the dorsal compartment, and $p d m$ specifies a proximodistal growth center [16-19] (note that $a p$ is also required for proper leg development: its loss of function leads to deletion of the fourth tarsal segment [20]). Furthermore, because ap and $p d m$ are expressed in the developing book gills, book lungs, tubular tracheae, and spinnerets of chelicerates, it has been argued that these opisthosomal structures, like crustacean gills and insect wings, were modified from the dorsal elements of ancestral arthropod limbs, and that shared ancestral ventral elements (legs) were altogether lost from the chelicerate opisthosoma [13]. This apparently branched, plesiomorphic limb architecture for arthropods, coupled with the fact that the parapodia of certain polychaetes, like those of Neanthes, are conspicuously branched appendages bearing dorsal (notopodial) and ventral (neuropodial) divisions, raises the question as to whether this trait is ancestral for protostomes. If annelids and arthropods inherited a homologous limb architecture with a pronounced dorsal-ventral bifurcation, then we would expect ap expression in Neanthes to occur extensively throughout developing notopodia.

The expression and function of $\lim 1$ in arthropod appendages has so far been examined in only Drosophila and the red flour beetle Tribolium castaneum, but it is required in both of these insects for proper proximodistal patterning. In Drosophila, lim1 expression in leg imaginal discs corresponds to the coxal, femoral, lower tibial, and pretarsal segments. Its transcripts are also present in the first and second segments and aristae of developing antennae. These portions of the legs and antennae are lacking or severely deformed in $\lim 1$ loss-of-function mutants [20,21]. The $\lim 1$ ortholog of Tribolium is expressed in proximal, middle, and distal domains within developing legs [22], as well as in antennal and gnathal appendages prior to their outgrowth [23]. Knockdown of Tribolium lim1 by RNA interference produces malformed appendages, usually with shortened and fused segments [23-25]. Because many aspects of appendage patterning appear to be conserved in general across diverse arthropods [26-29], and because mechanisms of proximodistal leg patterning may even be conserved throughout the Panarthropoda [30], it is reasonable to anticipate a role for $\lim 1$ in arthropod proximodistal pattering outside of insects, and to select $\lim 1$ as a gene of interest in the study of protostome appendage evo-devo. If the proximodistal axes of arthropodia and parapodia are homologous, then we expect lim1 expression in Neanthes to reflect a role in the patterning of this axis.

In addition to inferring the evolutionary relationship between parapodia and arthropodia, we analyze $a p$ and lim1 expression in Neanthes to explore their involvement in lophotrochozoan neural differentiation. Studies of Lhx genes in model ecdysozoans and deuterostomes suggest this gene family specified and maintained neural subtypes and regulated the targeting of axonal projections in ancestral bilaterians [31]; a comparison of ap and lim1 function in fly and vertebrates illustrates this putative conservation. In the central nervous system of Drosophila, ap controls axonal pathfinding and fasciculation of particular 
interneurons [32,33], and it establishes and maintains the identities of FMRF-amide- and leucokinin-producing neurons [34,35]. Similarly, the vertebrate ap orthologs $L h x 2$ and $L h x 9$ confer the rostral orientation of axonal projections of particular spinal cord interneurons [36], and their expression in vertebrate brains is consistent with overlapping and distinct roles in specifying and maintaining particular neural identities [37-39]. Suggesting conservation of olfactory development and physiology, $L h x 2$ is required for olfactory sensory neuron identity in vertebrates [40], and $a p$ is expressed in adult fly olfactory organs [41].

As in ap, Drosophila lim1 is responsible for guiding neuronal processes to their targets; an example is its control over the dendritic growth of projection neurons to antennal lobe glomeruli [42]. The vertebrate $\lim 1$ orthologs $L h x 1$ and $L h x 5$ confer the caudal orientation of axonal projections of certain spinal cord interneurons [36]. Although lim1's function in the fly nerve cord is not yet known, it is expressed in a subset of developing interneurons and in motor neurons that innervate dorsal segmental muscles [43]. The latter expression pattern, coupled with the fact that $L h x 1$ in vertebrates directs spinal cord motor axons to dorsal limb muscles [44,45], suggests conserved organization of a bilaterian motor circuit. Lastly, mammalian $L h x 1$ and $L h x 5$ cooperate in assigning identities to post-mitotic neurons, such as Purkinje cells [46] and GABAergic inhibitory neurons [47]. The above observations lead to a prediction of early and persistent $a p$ and $\lim 1$ expression in numerous domains of the differentiating central nervous system of Neanthes. Furthermore, $a p$ and $\lim 1$ domains should be largely distinct from one another, and ap expression should occur in developing olfactory organs.

We report detailed observations of $a p$ and lim 1 expression during post-embryonic development in Neanthes. We find that both genes are expressed in pre-morphogenetic and outgrowing parapodia, but in patterns that are not consistent with the predictions made above. In the nervous system, expression is largely consistent with the putative ancestral role of bilaterian Lhx genes in regulating the differentiation and maintenance of neuronal subtypes. Our observations also suggest a LIM code for parapodial myoblast diversification, as well as instances of co-optive evolution of Lhx function in annelids. For example, lim1 mRNAs accumulate in parapodial ligules, and ap mRNAs are observed in the jaw sacs and in the presumed Langdon's organs, which are paired cephalic sense organs known only in nereidids.

\section{Results}

Summary of juvenile development and gross morphology $N$. arenaceodentata is a direct developer whose hatchlings are extremely altricial, possessing only a rudimentary head and a few nascent trunk segments with minute parapodial buds. Although the hatchling nervous system reflects the basic organization of the adult nervous system, it undergoes substantial proliferation and differentiation during the first week of post-embryonic development [48]. Moreover, parapodial morphogenesis and neurogenic processes occur in newly added posterior segments throughout life. Because of these qualities, we felt it was unnecessary to analyze embryonic expression to test whether ap and lim1 potentially regulate parapodial development and neural differentiation/maintenance in this species. We overview the process of juvenile development and the basic anatomy of $N$. arenaceodentata in the following paragraph; for more complete descriptions see [48-50].

Embryos and juveniles of this species are brooded by their father within his mucoid tube for approximately 30 days post-fertilization $(\mathrm{dpf})\left(\right.$ at $\left.21^{\circ} \mathrm{C}\right)$. Embryos hatch from their egg capsules at $10 \mathrm{dpf}$. Hatchlings are teardrop-shaped and typically 450 to $500 \mu \mathrm{m}$ in length. They possess two to three chaetigers (chaetae-bearing segments), a slightly elongated posterior end, and an anterior mound - the nascent prostomium (the presegmental portion of the worm housing the brain). Posterior to the prostomium are four bilateral pairs of small ventrolateral buds. The two posterior-most pairs are nascent parapodia, whereas the two anterior-most pairs are developing anterior cirri, which eventually form long, slender sensory appendages. These cirri derive from segmental tissue, but fuse together to create the achaetous ring that ultimately integrates with the prostomium to form the head. By the mid 3-chaetiger stage (11 dpf), the sensory feeding palps form a pair of ventral buds on the prostomium, and the sensory anal cirri bud forth from the post-segmental pygidium. By the 4-chaetiger stage (13 dpf), the prostomium has enlarged significantly and bears emerging sensory antennae at its anterior terminus. In addition, a recognizable mouth forms on the ventral surface of the worm, immediately posterior to the palps, and several nascent segments with achaetigerous parapodial buds are present between the posterior-most (fourth) chaetiger and the pygidium, which bears a cleft-like anus between the anal cirri. Further juvenile development is characterized by the formation of eyes (by the 5-chaetiger stage; $14 \mathrm{dpf}$ ), lengthening of all appendages, emergence of an additional pair of anterior cirri (by the 6-chaetiger stage; $15 \mathrm{dpf}$ ), and a steady rate of segment addition (approximately 1 chaetiger/day). Yolk stores become depleted near the 20-chaetiger stage (approximately $30 \mathrm{dpf}$ ), and so juveniles begin dispersing from the parental tube to feed. Concerning parapodial morphology, the main dorsal division, or notopodium, bears the following processes (from dorsal to ventral): a dorsal cirrus, a dorsal notopodial ligule, a pair of chaetal lobes, and a ventral notopodial 
ligule. The main ventral division, or neuropodium, bears (from dorsal to ventral) a pair of chaetal lobes, a neuropodial ligule, and a ventral cirrus (see [48] for a discussion on the development sequence of parapodial processes in Neanthes). Parapodial cirri are sensory, whereas ligules are chiefly respiratory but apparently also capable of sensation $[48,51]$. Chaetae emerge from between the chaetal lobes and are anchored basally within an internal chaetal sac ensheathed by muscles that move the sac along an internal support rod (the acicula) to effect chaetal protraction and retraction [52].

\section{Orthology assessment of the Neanthes apterous- and lim1-related genes}

The apterous-related sequence of Neanthes [GenBank: HQ235024] is a 2,027 bp composite of three overlapping gene fragments assembled from 49 clones: 13 for the initial fragment, 14 for the $3^{\prime}$ RACE fragment, and 22 for the $5^{\prime}$ RACE fragment. It contains 318 bp of $5^{\prime}$ UTR (with six in-frame stop codons), a 1,260 bp coding region, and a 449 bp 3' UTR. The 3,174 bp lim1-related sequence [GenBank: HQ235025] was assembled from 44 clones: 12 for the initial fragment, 12 for the $3^{\prime}$ RACE fragment, and 20 for the $5^{\prime}$ RACE fragment. It contains 267 bp of $5^{\prime}$ UTR with two in-frame stop codons, a $1,494 \mathrm{bp}$ coding region, and a $1,413 \mathrm{bp} 3^{\prime}$ UTR. To determine affinities of these sequences within the LIMhomeodomain (LIM-HD) family of transcription factors, our phylogenetic analyses included representative sequences of the six canonical LIM-HD subfamilies. We did not include sequences from a possible seventh subfamily, the LIM-only proteins. These molecules lack homeodomains, but recent evidence suggests they originated from within the LIM-HD family after the divergence of sponges and ctenophores [53]. The resulting Maximum Likelihood (ML) tree (Figure 1) shows a strongly supported LIM-HD ingroup; note that we judge significance to be $\geq 70 \%$ bootstrap support for ML, Maximum Parsimony (MP), and Minimum Evolution (ME), and $>95 \%$ Bayesian posterior probability $(\mathrm{Ba})$. The LIMHD family is rooted between an Apterous-Arrowhead clade and a Tailup-Lim3-Lim1-Lmx clade, but these largest ingroup clades received significant or nearly significant support only by the ML method (72\% and $67 \%$, respectively). The tree includes two other nodes above the subfamily level: one uniting the Lim3, Lim1, and Lmx subfamilies, which received significant ML (75\%) and $\mathrm{Ba}(98 \%)$ support, and one uniting the Lim3 and Lim1 subfamilies, which received significant ML (80\%), MP (72\%), and ME (74\%) support, and nearly significant Ba (94\%) support. The higher-level relationships among LIM-HD subfamilies shown in our tree are nearly identical to those shown in the LIM-HD phylogeny of Srivastava et al. [54]. The only difference is that their tree places the
Tailup subfamily as sister to the Apterous-Arrowhead clade, instead of as sister to the Lim3-Lim1-Lmx clade. In our tree, the subfamilies themselves received robust support by all four methods, and the Neanthes apterous-related and lim1-related genes grouped within the Apterous and Lim1 subfamilies, respectively. Therefore, we firmly conclude that each is an ortholog of that subfamily, and we name these genes Nar-ap and Nar-lim1.

\section{Expression of Nar-ap}

At the hatchling stage, Nar-ap mRNAs are distributed widely in the head (Figure 2A; compare with Figure 2B). In particular, transcripts occur in many areas of the brain (Figure 2A, brackets), in anterior cells of the palp bases (Figure 2A, dashed ellipses), and in cells encircling the foregut opening (Figure 2A, asterisk). A bilateral pair of cell clusters within the pharynx expresses Nar-ap (Figure 2A, black double arrowheads), and low-level Narap activity occurs in segmentally iterated cell clusters within the nerve cord ganglia (Figure 2A, white double arrowheads). At the posterior end, Nar-ap expression is evident primarily in mesoderm (Figure $2 \mathrm{C}$, arrows) and in several ectodermal cells (Figure 2D, arrowheads).

Inspection of mid 3-chaetiger juveniles reveals that the Nar-ap pharyngeal expression corresponds to cells surrounding the developing jaws (Figure 2E). The late 3chaetiger stage is the only stage at which we observed Nar-ap expression in the achaetous ring; it occurred in two dorsal superficial cells (Figure 2F, white arrowheads), which are probably acetylated alpha-tubulin (AAT)immunoreactive tegumentary neurons that connect to the cephalic nervous system (data not shown). (Note that antibodies to AAT are used to label neuronal cell processes (axons and dendrites) and cilia; see below). Also at this stage, expression in the nerve cord ganglia is more evident, being present in discrete cell clusters of every segment (including nascent, achaetigerous segments) except those in the approximately posterior onethird of the worm (Figure 2G, white double arrowheads).

By the 4-chaetiger stage, Nar-ap-positive mesoderm is present in at least six nascent segments posterior to the main yolk mass (Figure $2 \mathrm{H}$, arrows), and the ectodermal expression (observed in five nascent segments) appears as laterally positioned stripes that vary in length (Figure 2I, staggered arrowheads). The brain's posterodorsal cortex shows particularly strong Nar-ap expression that encompasses cells at the posterior prostomial border (Figure 2J). A slightly deeper focal plane shows a distinct absence of expression in mid-lateral prostomial regions that include the developing eyes (Figure $2 \mathrm{~K}$, dashed boxes). Most other portions of the prostomium within this focal plane (predominantly brain) are Nar-ap-positive (Figure 2K). Deeper focal planes exhibit expression in bilaterally paired U-shaped expression 


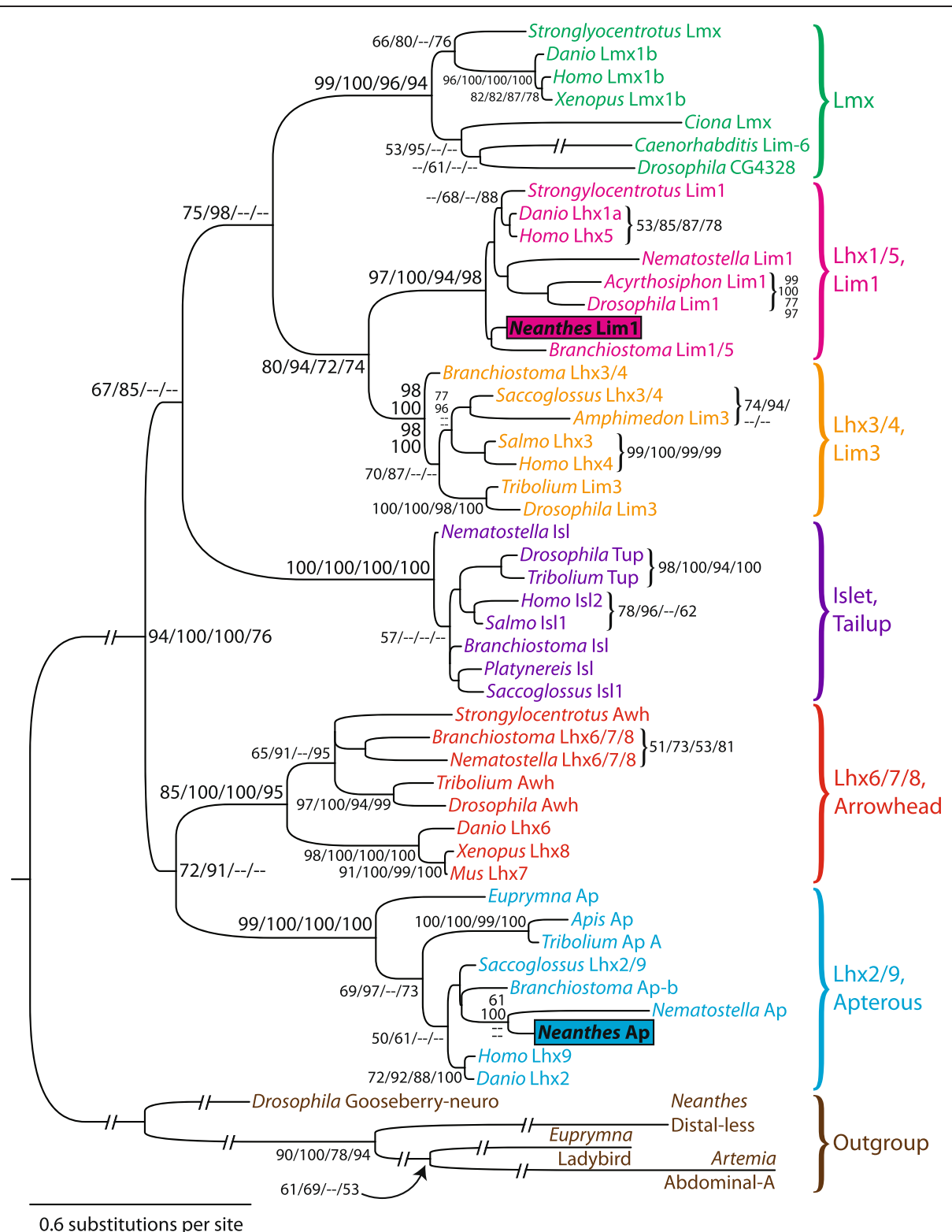

Figure 1 Maximum Likelihood phylogeny of the LIM-homeodomain family, rooted with four other homeodomain families. Robust support was found for all subfamilies. The Neanthes $\lim 1$ and apterous orthologs are highlighted with colored boxes. The four support values at each node are, in order: Maximum Likelihood bootstrap percentage, Bayesian posterior probability, Maximum Parsimony bootstrap percentage, and Minimum Evolution bootstrap percentage. Only values $\geq 50$ are shown. Branch lengths are proportional to molecular change (amino acid substitutions/site) between nodes; see scale bar for measurement. Lengths of the interrupted branches were halved to improve the figure's presentation. Vertebrate subfamily names precede Drosophila subfamily names to the right of each bracket. GenBank accession numbers for the analyzed sequences, in order from top to bottom of the tree, are: XP_790548, NP_001020338, NP_002307, NP_001083902, NP_001071756, NP_508204, NP_648567, ACA04473, NP_571291, NP_071758, BAH58087, XP_001945631, NP_572505, AEN75258, ABD59002, XP_002591838, NP_001158395, ACA04748, NP_001130018, EAW91078, XP_973330, NP_724161, XP_001638136, NP_476775, NP_001158279, NP_665804, ACl69553, XP_002609922, ABO93221, NP_001158468, XP_785118, XP_002609417, XP_001626470, XP_971202, NP_523907, NP_001004015, NP_001015899, CAA04012, AAV84105, XP_392622, NP_001139341, NP_001158443, XP_002592485, XP_001635417, AEN75257, NP_001014434, NP_001035099, NP_523862, ACN66454, AAV85467, ABD37012. 


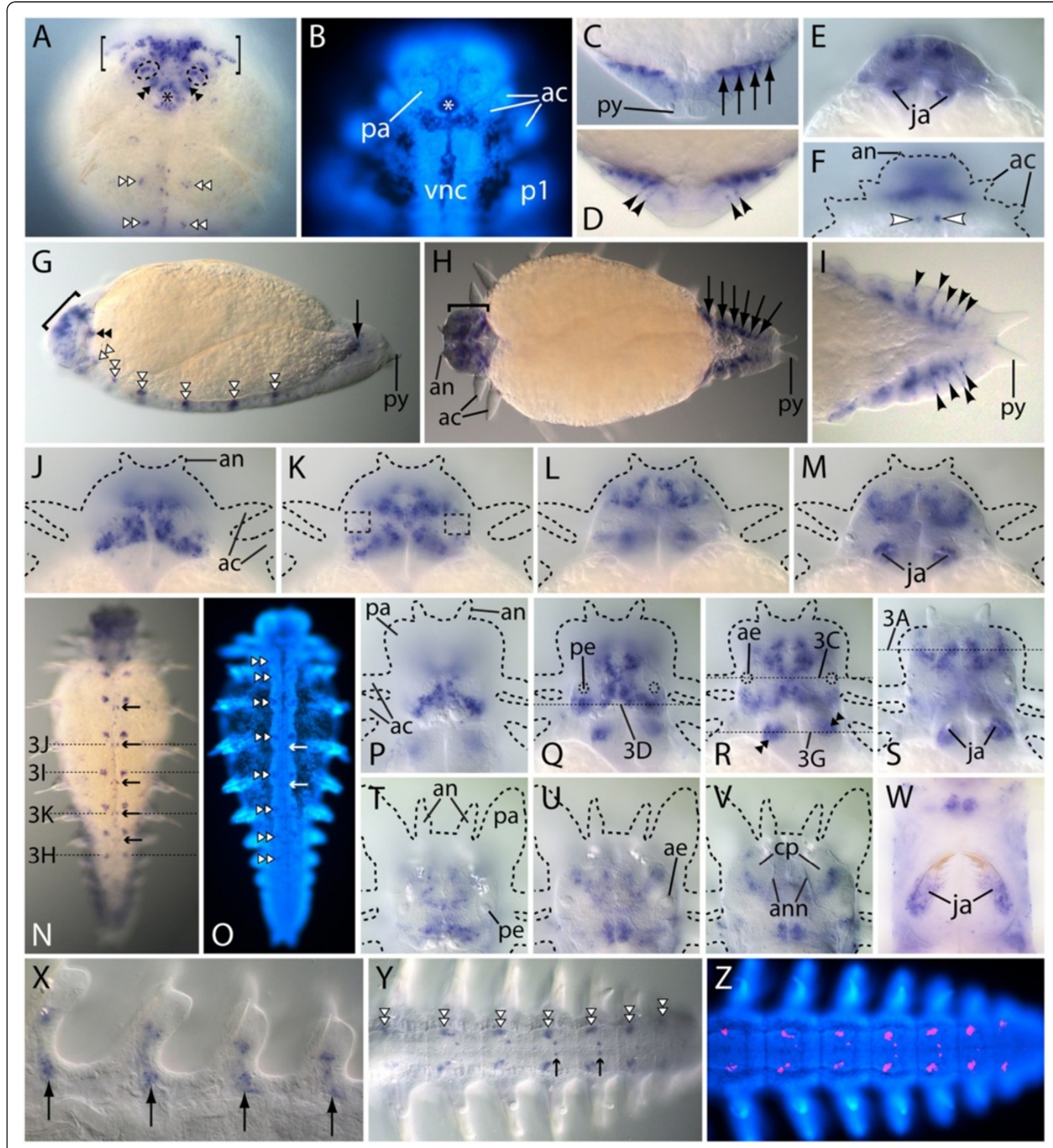

Figure $\mathbf{2}$ (See legend on next page.) 
(See figure on previous page.)

Figure 2 Expression of Nar-ap during juvenile development. (A), (B), (N), (O)), (Y), (Z) Ventral views, anterior to the top (but to the left in (Y),

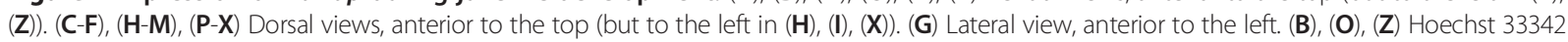
fluorescence $(\mathbf{B})$ is a different specimen than that shown in $(\mathbf{A}) ;(\mathbf{O})$ and $(\mathbf{Z})$ are the same specimen as that shown in $(\mathbf{N})$ and $(\mathbf{Y})$, respectively). $(\mathbf{J}-\mathbf{M})$, (P-S), (T-V) Sets of contiguous focal planes (dorsal to ventral) of the head, which is outlined with dashes. Expression domains in this figure are indicated by the following symbols: arrowheads (black) ectoderm of nascent segments, arrowheads (white) presumed tegumentary neurons, arrows (large) dorsal mesoderm, arrows (small) medial cell clusters of the nerve cords, brackets brain, dashed ellipses palp bases, double arrowheads (black) pharynx, double arrowheads (white) lateral cell clusters of the nerve cords. (A-D) Hatchling stage. (A), (B) Anterior end. An asterisk marks the foregut lumen. (C), (D) Posterior end (same specimen; (C) is a Nomarski image and (D) is a brightfield image). (E) Mid 3-cheatiger stage, anterior end. (F), (G) Late 3-chaetiger stage. (F) Anterior end, out of focus and outlined with dashes. (H-M) 4-chaetiger stage. The posterior end is shown in (I), and dashed

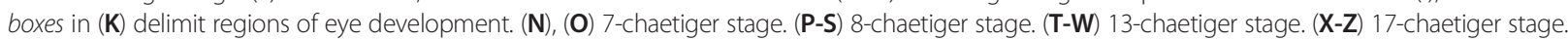
(X) Notopodia of the 4 posterior-most chaetigers. (Z) Expression is false-colored red. ac anterior cirri, ae anterior eye, an antenna, ann antennal nerve, cp corpus pedunculus, ja jaw, p1 1st parapodium, pa palp, pe posterior eye, py pygidium, vnc ventral nerve cords.

domains occupying the anterior half of the head (Figure 2L, M), and persistent expression occurs around the jaws (Figure $2 \mathrm{M}$ ).

In 7-chaetiger juveniles, the ventral nerve cords (VNCs) exhibit prominent bilateral pairs of Nar-ap-positive cell clusters that associate with eight pairs of ganglia, including the subesophageal ganglia (most anterior) (Figure $2 \mathrm{~N}$; Figure 2O, double arrowheads). In addition, a smaller bilateral pair of Nar-ap-positive VNC cell clusters is evident posterior and medial to each of the larger cluster-pairs (Figure $2 \mathrm{~N}$ and $\mathrm{O}$, arrows). In the 8-chaetiger juvenile brain, Nar-ap mRNAs continue to accumulate in the posterodorsal cortex (Figure 2P); this staining forms the bottom half of an X-like pattern, the top half of which is seen in the next two deeper focal planes (Figure 2Q, R). As was the case in 4-chaetiger juveniles, a large region anterior as well as medial to the eyes is devoid of Nar-ap activity (Figure 2Q, R). A slightly deeper focal plane exposing an anteroventral portion of the brain (Figure $2 \mathrm{~S}$ ) shows persistent expression in the U-shaped patterns described above for 4-chaetiger juveniles. Starting in the medial brain, each ' $U$ ' wraps widely around the 'antennal ganglion' (sensu [48]) to a position between the antenna and palp at the prostomium's anterior terminus. We also observed continued expression around the jaws (Figure 2R (double arrowheads), 2S).

Figure 3 presents additional details of Nar-ap expression in 7- and 8-chaetiger juveniles. Comparison of a transverse section halfway through a prostomial Ushaped expression domain (Figure 3A; see dashed line in Figure 2S) with an equivalent section from an AATlabeled specimen (Figure 3B) reveals that the medial portion of a ' $U$ ' likely consists of cells in the brain's anterodorsal cortex and, ventral to this, in a stomatogastric ganglion (see [48]). The lateral portion of each ' $U$ ' likely corresponds to a Langdon's organ (Figure 3B) (see $[55,56])$. Note that we deduced this organ's identity from the relative positions of the neighboring and more distinctive antennal nerve and corpus pedunculus, and from its own telltale sensory cilia (Figure 3B, inset; see also [48]). Expression at this transverse level of the head also occurs in the palp's lateral portion, possibly in sensory organs (Figures 3A, B).

In a section through the anterior eyes (Figure $3 C$; see dashed line in Figure 2R), Nar-ap-positive cells occupy a medial domain dorsal to the neuropil. A comparable section from an AAT-labeled specimen (Figure 3E) reveals a previously unknown dorsal ciliated organ, possibly connected to the neuropil via a bilateral pair of oblique nerves. Description of this organ is beyond the scope of the current work, but coincident Nar-ap expression (Figure 3C) suggests a role for this gene in its development.

In a section taken just posterior to the posterior eyes (Figure 3D; see dashed line in Figure 2Q), Nar-ap expression appears limited to the dorsolateral and ventromedial sides of the brain. Comparable sections of an AAT-labeled specimen (Figure 3F) reveal that the nuchal organs (chemosensory organs comprised of a nuchal nerve, a cluster of sensory cells, their dendrites, external ciliation, and internal retractor muscles; see, for example, [48,57]) occupy ventrolateral positions in this portion of the brain. The lack of Nar-ap expression here (Figure 3D, dashed ellipses) suggests minimal Nar-ap function in nuchal organ differentiation. This result goes against our above prediction (see Background) of ap expression in Neanthes olfactory organs.

A transverse section through the jaws indicates that pharyngeal expression of Nar-ap is limited to the epithelial sac surrounding each jaw (Figure 3G). In regard to the Nar-ap-expressing VNC cell clusters, transverse cross sections through each cluster type (see dashed lines in Figure $2 \mathrm{~N}$ ) reveal that, first, the larger anterior type, in both a nascent segment (Figure $3 \mathrm{H}$ ) and a more mature segment (Figure 3I), includes no fewer than ten cells (accounting for cluster thickness along the anteroposterior axis) and occupies much of the lateral portion of each ganglion. Second, the smaller clusters reside medially and at a median or basal level in each ganglion, and consist of no fewer than three cells (Figures 3J, K).

Transverse sections through the posterior portion of a 7-chaetiger juvenile clarify spatial details of Nar-ap expression in nascent segments and outgrowing parapodia 


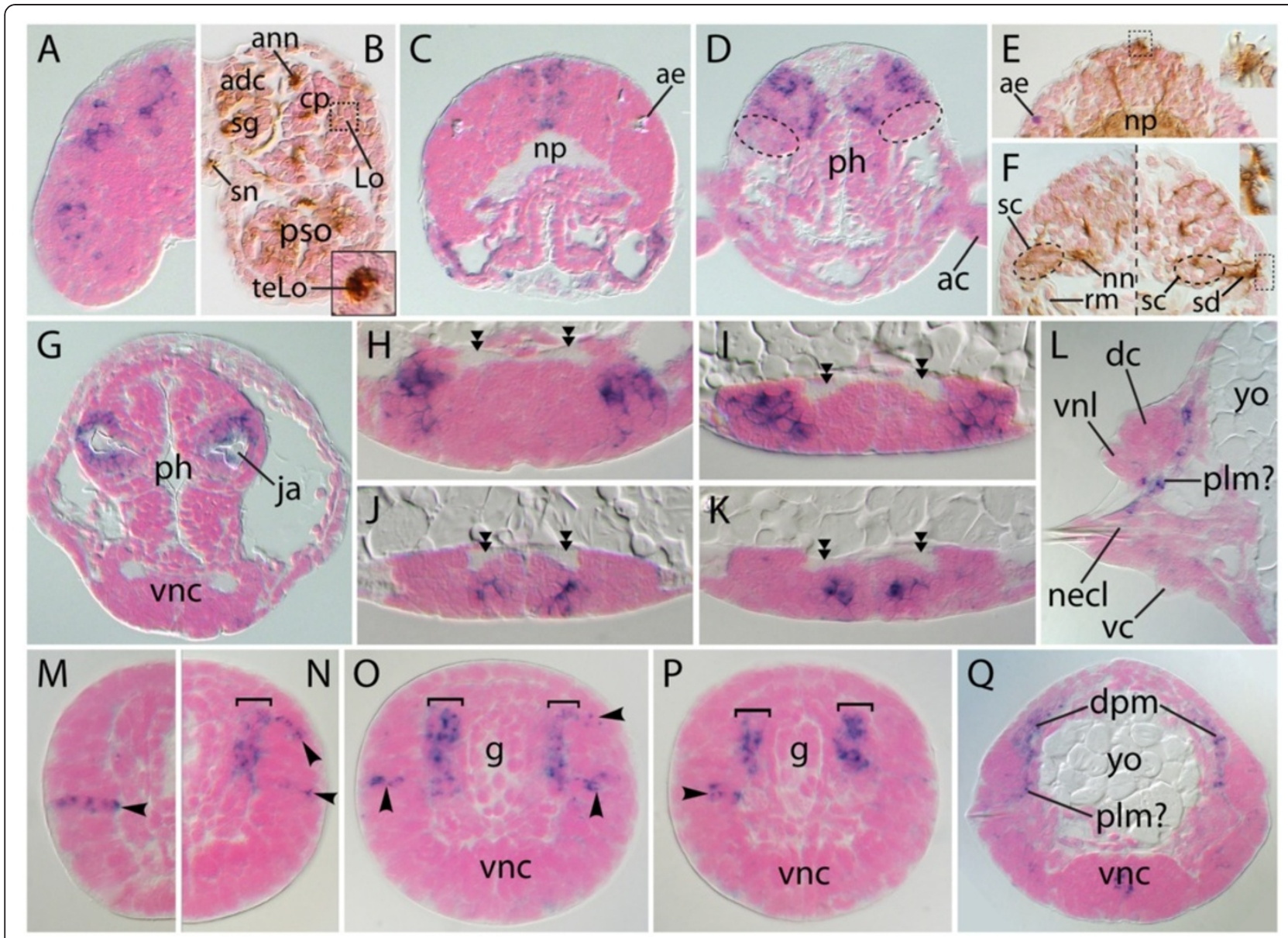

Figure 3 Histologic cross sections showing further details of Nar-ap expression. All sections are orthogonal to the anteroposterior (AP) axis; dorsal is to the top. $(\mathbf{A}-\mathbf{G})$ 8-chaetiger stage. (H-Q) 7-chaetiger stage. (B), (E), (F) Acetylated a-tubulin immunolabeling; cilia and neuronal cell processes are brown. (A), (B) Just posterior to the antennal ganglia, $10 \mu \mathrm{m}$ anterior to the brain's neuropil. Inset image in (B) is $10 \mu \mathrm{m}$ anterior to, and a blowup of, the Lo region delimited with a dashed box. (C) Cephalic section at the level of the anterior eyes. (D) Dashed ellipses circumscribe areas expected to each contain a nuchal organ. (E) Same AP position as (C). The inset ciliary tuft is $5 \mu \mathrm{m}$ anterior to, and a blowup of, the boxed area. (F) Same AP position as (D), showing nuchal organ locations in the posterior brain. The three parts of this panel - left, right, and inset ciliary tufts (a blowup of the boxed area) - are consecutive sections $5 \mu \mathrm{m}$ apart (from anterior to posterior, respectively). (G) Pharyngeal section at the level of the jaws. (H-K) Ventral nerve cords. Double arrowheads point to longitudinal nerve tracts. (L) Posterior section through a sixth parapodium. (M-Q) Pre-chaetigerous segments near the posterior growth zone, arranged from youngest to more mature and showing ectodermal (arrowheads) and mesodermal (brackets) expression domains. adc anterodorsal cortex of the brain, ae anterior eye, ann antennal nerve, $c p$ corpus pedunculus, dc dorsal cirrus, g gut, Lo Langdon's organ, ned neuropodial chaetal lobe, nn nuchal nerve, np neuropil, $p / m$ ? presumed parapodial levator muscle, pso palp sense organs, rm nuchal organ retractor muscle, sc nuchal organ sensory cells, $s d$ nuchal organ sensory dendrites, $\mathrm{s} g / \mathrm{n}$ stomatogastric ganglion/nerve, teLo terminal endings of sensory-cell peripheral processes from Langdon's organ, $v c$ ventral cirrus, vnc ventral nerve cords, vnl ventral notopodial ligule, yo yolk.

(Figures 3L-Q). First, ectodermal expression, observed only prior to parapodial outgrowth, exists in narrow rows that are one to two cells in height, vary in length, and number two per hemisegment, with one residing at a dorsal level and the other residing at a roughly median level (Figures 3M-P, arrowheads; multiple sections are presented to show variation in the length of these rows, and that their positions do not always overlap - with each other or with Nar-ap-positive mesoderm). Second, mesodermal expression occurs in thick dorsolateral cell blocks that are delimited roughly by the positions of the
Nar-ap-positive ectodermal rows (Figures 3N-P). In a slightly older segment (Figure 3Q), the position of Narap-positive mesodermal cells corresponds to the dorsal parapodial muscles [48,52]. Moreover, the narrow band of Nar-ap-positive mesoderm extending ventrolaterally from the vicinity of the dorsal parapodial muscles to the neuropodial chaetal lobe likely corresponds to the developing parapodial levator muscle (Figures 3L, Q; see also [48,52]).

At the 13-chaetiger stage, Nar-ap activity persists in the brain's posterodorsal cortex (Figure 2T), and appears to be continuous with posteroventral brain expression 
(Figures 2U, V), but expression posterior to and between the eyes has become less intense (Figures 2T, U). The anterior U-shaped domains continue expressing Nar-ap in the brain's anterodorsal cortex (Figure 2U). Ventrally, however, expression in the medial portion of each ' $U$ ' (that is, expression in the presumed stomatogastric ganglia) appears to have largely ceased, but the lateral expression persists (Figure 2V). This staining wraps around the lateral sides of each corpus pedunculus, localizing to the expected positions of the Langdon's organs (see Figure 5E of [48]), corroborating our above presumption based on AAT labeling and sections of the 8 -chaetiger stage prostomium. In the jaw sacs, Nar-apexpressing cells are detected only in specimens having undergone longer color reactions (Figure $2 \mathrm{~W}$ ), indicating attenuation of expression (note that negative control experiments run with sense probes for the same amount of time showed no equivalent staining; also, the Nar-appositive cell clusters near the top of Figure $2 \mathrm{~W}$ reside in the posteroventral brain).

In accord with the pattern observed in 7-chaetiger juveniles, outgrowing parapodia of 17-chaetiger juveniles also express Nar-ap in what appears to be a dorsal subectodermal domain, but only within the posterior portion of the segment (Figure 2X). This indicates that the anterior set of dorsal parapodial muscles develop in the absence of Nar-ap activity. Nar-ap expression patterns in the VNCs of 17-chaetiger juvenile posterior segments (Figure 2Y, Z) are identical to those observed at earlier stages, indicating that serially homologous Nar-ap-positive VNC cell clusters develop in each newly added segment.

\section{Expression of Nar-lim 1}

In hatchlings, the head is a dominant territory of Narlim1 activity; its transcripts are detected around the foregut opening (Figure 4A, asterisk), in cells circumscribing the palps, and within the brain (Figure 4A, brackets). Within the pharynx, two pairs of bilateral cell clusters, one dorsal and one ventral, are Nar-lim1-positive (Figure 4A, double arrowheads). Within the VNCs, Nar-lim1 transcription extends beyond regions expressing Nar-ap to the extent that Nar-lim1 staining reflects the basic nerve-cord structure (Figure 4A; compare with Figure 2A). At the hatchling posterior end, nascent segments show intense Nar-lim1 signal in preformed parapodia (Figures $4 \mathrm{~B}, \mathrm{C}$ ).

At the mid 3-chaetiger stage, a superficial ventral view of the head (Figures 4D, E) reveals persistent Nar-lim1 expression around the foregut opening and between the palps. Other Nar-lim1-positive cells reside in the furrows between the outgrowing palps and anterior cirri, and at the posterior bases of these cirri. A deeper focal plane (Figure 4F) captures intensely staining, bilaterally paired expression domains in the medial brain that roughly parallel the superficial/ventral columns of Nar-lim1-positive cells between the palps. Brain regions posterolateral to these medial domains also exhibit considerable Nar-lim1 expression (Figure 4F). Parapodial expression at this stage (Figure 4G, ellipses) can be discerned in ectoderm (lateralmost staining) and mesoderm (Figure 4G, between parallel red lines). Expression immediately anterior to the pygidium (Figure 4G, arrowheads; pygidium outlined) does not appear to be in register with the segmentally repeated parapodial staining, and hence may be associated with the posterior growth zone (PGZ). However, to rule out that this expression reflects an earlier stage of parapodial development, it would need to be mapped relative to the expression of genes that mark the PGZ (for example, caudal, even-skipped) and/or newly added segments (for example, hedgehog, wingless, engrailed, NK genes) [7,58-60].

In late 4-chaetiger juveniles, Nar-lim1 transcripts accumulate in every VNC ganglion (Figure 4H; compare with Figure 4I). A segmentally repeated expression pattern lateral to the nerve cords and posterior to the parapodia is also evident (Figure $4 \mathrm{H}$, boxes). While further investigation is required to determine the identities of these Nar-lim1-positive cells, we provisionally assign them to the segmental peripheral nervous system (see [48,61]). In the brain, clusters of Nar-lim1-positive cells populate the posterodorsal cortex, but in a manner lacking a strong bilateral pattern (Figure 4J). At a slightly deeper focal plane (Figure 4K), Nar-lim1 expression is widespread in the brain's anterodorsal cortex, occurring in numerous cell clusters with a somewhat stronger bilateral pattern. Expression in the anteromedian brain cortex (Figure 4L) changed little from that described above for mid 3-chaetiger juveniles, and it appears to be more or less continuous with expression in the brain's anteroventral cortex (Figure 4M): at both stages, and in both the anteromedian and anteroventral brain regions, staining occurs in the lateral-most ganglia and in a large pair of ganglia abutting the midline anterior to the neuropil (Figures 4L, M; compare with Figure 4F). We also observed continued pharyngeal expression (double arrowheads in Figures 4J, K). Parapodia at the late 4chaetiger stage have undergone modest outgrowth, and their Nar-lim1 transcripts associate with the developing ventral notopodial ligule, the chaetal bases, and the neuropodial ligule (Figures $4 \mathrm{~N}, \mathrm{O}$ ).

At the 7-chaetiger stage, ongoing Nar-lim1 activity occurs in the VNCs (Figure 4P; compare with Figure 4Q), presumed segmental peripheral nervous system (Figure 4P, boxes), and pharynx (Figures 4R-U, double arrowheads). Expression in the head is complex (Figures 4R-U), but despite this, staining in anteroventral head regions (Figures 4T, U) resembles previously described stages. The aforementioned parapodial and presumed PGZ expression 


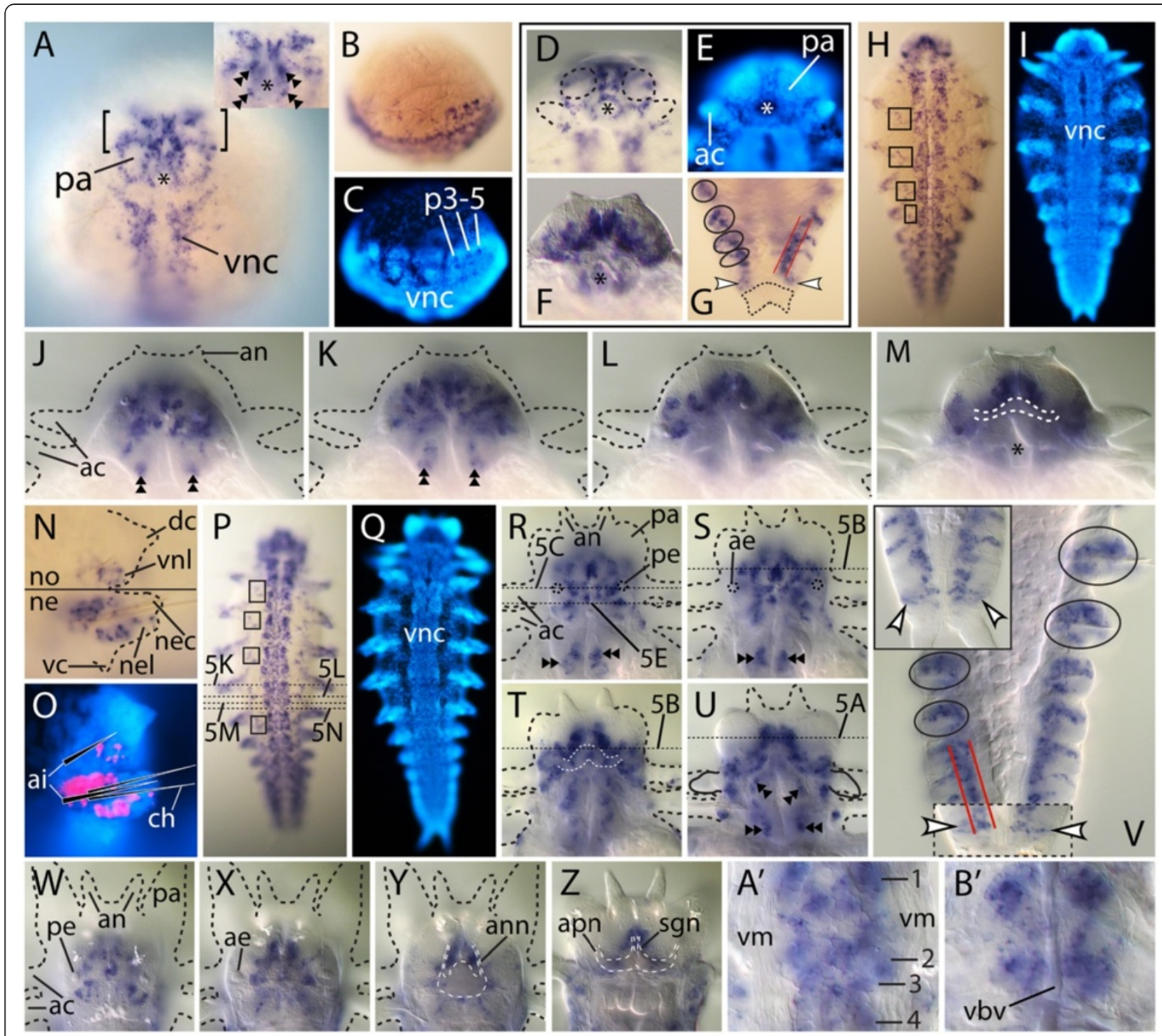

Figure 4 Expression of Nar-lim1 during juvenile development. (A), (D), (E), (G), (H), (I), (P), (Q), (U), (V), (Z-B') Ventral views, anterior at top. (B), (C) Ventrolateral views, anterior at left. (F), (J-M), (R-T), (W-Y) Dorsal views, anterior at top. (N), (O) Anterolateral parapodial views, distal at right.

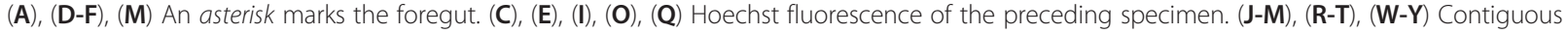
cephalic focal planes (dorsal to ventral). (M), (T), (Y), (Z) White dashes outline visible neuropil and cephalic nerves. Expression domains are indicated by: arrowheads presumed posterior growth zone, boxes presumed peripheral neurons, brackets brain, double arrowheads pharynx, ellipses parapodia, parallel red lines nascent segmental mesoderm. (A-C) Hatchlings. (A) The inset image shows a deeper pharyngeal focal plane. (D-G) Mid 3-chaetiger stage. (D-F) Anterior end. (D) Cephalic appendages are outlined. (F) Mid focal plane of the brain. (G) Posterior end, with pygidium outlined. (H-O) Late 4-chaetiger stage. (N), (0) Third parapodium. (O) False-colored expression and schematic bristles. (P-U) 7-chaetiger stage. (V) 7-chaetiger juvenile (inset image) and 9-chaetiger juvenile (main image) posterior end. The boxed region is from a shallower focal plane. (W-Z) 13-chaetiger stage. $\left(\mathbf{A}^{\prime}\right)$, ( $\left.\mathbf{B}^{\prime}\right)$ 20-chaetiger stage. Contiguous focal planes of VNC ganglia in a mid-body segment $\left(\left(\mathbf{A}^{\prime}\right)\right.$ is at a median focal level, and $\left(\mathbf{B}^{\prime}\right)$ is deeper). Numbered lines in $\left(\mathbf{A}^{\prime}\right)$ indicate the root locations of segmental nerves 1 to 4 in the right hemisegment. ac anterior cirrus, ae anterior eye, ai acicula, an antenna, ann antennal nerve, apn axial palp nerve, $d c$ dorsal cirrus, ne neuropodium, nec neuropodial chaetal lobe, nel neuropodial ligule, no notopodium, p3-5 third to fifth parapodia, pa palp, pe posterior eye, sgn stomatogastric nerve, $v c$ ventral cirrus, $v b v$ ventral blood vessel, vm ventral longitudinal muscle, vnc ventral nerve cords, vnl ventral notopodial ligule.

patterns are also evident in 7- and 9-chaetiger juveniles (Figure 4V). Analysis of transversely sectioned specimens helps to clarify details of Nar-lim1 expression at this stage (Figure 5). A section through the anterior prostomium (Figure 5A; see dashed line in Figure 4U) shows narrow strips of Nar-lim1-positive cells linking two other Narlim1-positive domains: the ganglia anterior to the neuropil, and the tissue between the palp bases. A section through the anterior neuropil (Figure 5B; see dashed line in Figure 4S, T) reveals Nar-lim1 activity in the epithelium 


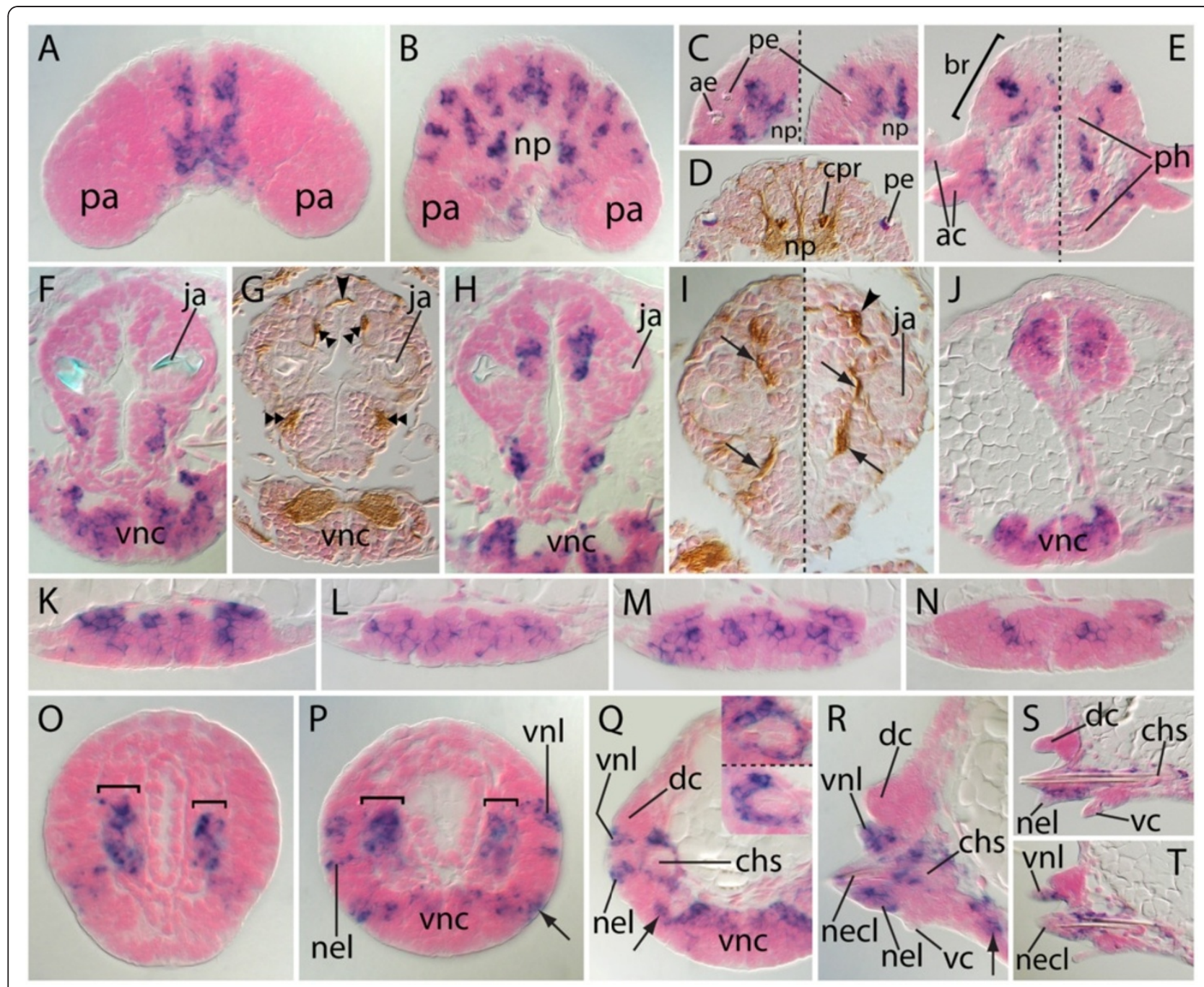

Figure 5 Histologic cross sections of 7-chaetiger juveniles showing further details of Nar-lim 1 expression. All sections are orthogonal to the AP axis; dorsal is to the top. Dashed lines separate sections spaced apart by $5 \mu \mathrm{m}$ in $(\mathbf{C}),(\mathbf{E}),(\mathbf{Q})$ and $10 \mu \mathrm{m}$ in (I) (the more posterior section is to the right or below the line). (D), (G), (I) Acetylated a-tubulin immunolabeling. (A) Same AP position as Figures 3A, B. (B) Anterior-most level of the brain's neuropil. (C) Upper quadrant of the head; the mid-sagittal plane is flush with each image's right edge. (D) Same AP position as (C). (E) Posterior brain and anterior pharynx. (F-J) Three positions within the pharynx: anterior jaws $(\mathbf{F}),(\mathbf{G})$, posterior jaws $(\mathbf{H})$, (I), and caudal-most $(\mathbf{J})$. Arrowheads point to exposed portions of commissural nerves; double arrowheads point to longitudinal nerves; arrows point to exposed portions of medial nerves connecting ipsilateral ganglia. (K-N) Various positions within the 5th and 6th ganglion pairs of the ventral nerve cords. (O-T) Nar-lim 1 expression during parapodial development. Brackets indicate mesodermal expression; arrows mark expression in parapodial ganglia. (0) Nascent segment nearest the pygidium. (P) Nascent segment approximately $20 \mu \mathrm{m}$ anterior to (0). (Q) Youngest outgrowing parapodium; approximately $50 \mu \mathrm{m}$ anterior to (P). Inset images show additional sections through the chaetal sac, 10 and $15 \mu \mathrm{m}$ anterior to main image, respectively. (R) Youngest chaetigerous (sixth) parapodium. (S), (T) First pair of parapodia (left and right, respectively) from the same section; one shows the nel (S), and the other the $\mathrm{vnl}(\mathbf{T})$. ac anterior cirri, ae anterior eye, br brain, chs neuropodial chaetal sac, cpr ciliary photoreceptor cells, dc dorsal cirrus, ja jaw, necl neuropodial chaetal lobe, nel neuropodial ligule, np neuropil, pa palp, pe posterior eye, ph pharynx, vc ventral cirrus, vnc ventral nerve cords, $v n /$ ventral notopodial ligule.

between the palp bases, and in no fewer than eight bilateral cell-cluster pairs within the brain. In the ocular region (Figure 5C; see dashed line in Figure 4R), Nar-lim1positive domains medial to the posterior eyes appear to co-localize with internal brain structures exhibiting intense AAT labeling (Figure 5D). These are in all likelihood the ciliary photoreceptor cells [62]. A posterior transverse section of the head (Figure 5E; see dashed line in Figure 4R) documents Nar-lim-positive cell clusters in dorsolateral and ventral sectors of the brain that potentially overlap with Nar-ap-positive cells and the nuchal organs, respectively. Other expression at this transverse level is present in the achaetous ring; it occurs just medial to the anterior cirri, presumably in cirral ganglia (Figure 5E).

In transverse sections of the 7-chaetiger juvenile pharynx, we observed Nar-lim1 activity in bilaterally paired, 
ventrolateral cell groups just below the anterior jaws (Figure 5F). Comparable AAT-labeled sections reveal a ventral longitudinal nerve adjacent to each cell group (Figure 5G). In addition, Nar-lim1-positive cells neighbor dorsal longitudinal nerves in sectors that are above and medial to the jaws (compare Figures $5 \mathrm{G}$ and $\mathrm{H}$ ). Because Nar-lim1-positive pharyngeal cells associate with neural elements (for example, longitudinal nerves, dorsoventral nerves connecting ipsilateral cell groups, and commissural nerves connecting contralateral cell groups) (Figures 5G, I), we conclude that they are integrated into pharyngeal ganglia. Nar-lim1 expression is also evident posterior to the jaws (Figures 5E, J), in ganglia that also express dachshund and optomotor blind [8].

Transverse sections through the fifth and sixth ganglion pairs clarify the segmental expression pattern of Nar-lim1 within the 7-chaetiger-stage VNCs (see dashed lines in Figure 4P). In a mid-segmental registry, near the second segmental nerve roots (see $[40,61]$ ), VNC expression is most intense within dorsolateral sectors of the ganglia (Figure 5K). Posterior in the segment, near the fourth segmental nerve roots, light Nar-lim1 expression occurs at a median level across the VNC (Figure 5L). In the anterior of the adjacent segment, near the first segmental nerve roots, expression is similar to that seen in Figure $5 \mathrm{~K}$, but with basal extension of lateral expression (Figure 5M). In VNC regions recognized by apparent gaps in expression, that is, between the first and second segmental nerves, expression is primarily restricted to a bilateral pair of cell clusters lying near the midline at a median level within the cords (Figure $5 \mathrm{~N}$ ).

Analysis of transverse sections through the newly added posterior segments of 7-chaetiger juveniles enabled us to precisely identify the developing parapodial structures that express Nar-lim1. Transcripts first occur in thick blocks of cells in nascent ventral mesoderm (Figure $5 \mathrm{O}$ and P, brackets). As parapodial outgrowth proceeds, these cells come to surround the neuropodial chaetal sac (Figures 5Q-S), forming the neuropodial chaetal sac muscles. The notopodial chaetal sac develops later than that of the neuropodium, and no evidence of Nar-lim1 expression in its musculature was observed. Prior to outgrowth, ectodermal Nar-lim1 expression is evident in three distinct domains (Figure 5P); two align roughly with the top and bottom of the mesodermal expression domain, and one lies just lateral to the nerve cord. The identities of these domains become clear as outgrowth proceeds. The expression domain adjacent to the nerve cord forms the medial cells of the parapodial ganglion, and the successively more dorsal domains form the anlagen of the neuropodial ligule and the ventral notopodial ligule (Figures 5Q-S). Morphogenesis of the dorsal notopodial ligule occurs during later stages of parapodial outgrowth [48] and was not observed in this study.
In 13-chaetiger juveniles, the posterior brain bears two separate Nar-lim1-positive cell clusters posterior to each posterior eye, and a pair of clusters on the midline between these eyes (Figure 4W). A deeper focal plane (Figure 4X) shows a Nar-lim1-positive cluster medial to each anterior eye. How these patterns relate specifically to similar patterns in earlier stages is difficult to judge. However, one pattern remains comparatively static among the stages: medial expression in the anterior brain. This occurs in dorsal, median, and ventral levels of the cortex (Figures $4 \mathrm{X}, \mathrm{Y}, \mathrm{Z}$, respectively), where the median and ventral expression together corresponds to a pair of stomatogastric ganglia (of the first pair of stomatogastric nerves) [48]. We observed continued pharyngeal and VNC expression at this stage (data not shown), as well as in 20-chaetiger-juvenile VNC ganglia (Figures 4A', B'), which exhibit Nar-lim1 activity that is largely consistent with the VNC patterns described for earlier stages, suggesting persistent transcription in the same cell types.

\section{Discussion}

\section{Apterous, lim 1, and appendage evo-devo}

We previously assayed the expression of Neanthes Distal-less, dachshund, and optomotor blind to investigate whether conserved mechanisms of appendage development exist across the Bilateria [8]. Expression of these genes does not map to the dorsoventral and proximodistal fields that might be predicted by comparison to arthropod and vertebrate appendages, implying independent evolution of annelid appendage development. Here, we supplement our previous work by discussing whether parapodial expression of Nar-ap and Nar-lim1 supports conservation of limb developmental between bilaterian phyla. As outlined in the Background section, extensive Nar-ap expression in developing notopodia would support homology of limb organization into dorsal and ventral elements in annelids and arthropods. However, the two narrow rows of Nar-ap-positive cells in parapodial ectoderm (arrowheads in Figure 2I and Figures 3M-P) cease their expression prior to outgrowth, and notopodial Nar-ap expression during outgrowth is limited to muscles. Therefore, Nar-ap activity is not similar in its broad scope to the activity of $a p$ homologs in the dorsal division of the arthropod limb; hence this comparison yields little support for a branched appendage architecture in the common ancestor of lophotrochozoans and ecdysozoans. In addition, parapodial Nar-ap expression bears minimal resemblance to the limb activities of vertebrate ap orthologs, $L h \times 2$ and $L h x 9$, which function in the progress zone (distal mesoderm) to integrate outgrowth with anteroposterior and proximodistal patterning $[63,64]$. The vertebrate $\lim 1$ orthologs, $L h x 1$ and $L h x 5$, play no role in limb 
development [64], but lim1 in Drosophila and Tribolium is expressed in multiple developing leg segments, where it is required for proper proximodistal patterning [20-22,25]. Nar-lim1 expression in parapodia does not appear similarly organized. Rather, it may play roles in the morphogenesis of ligules, and in the development of a specific set of muscles. These contrasting patterns of ap and $\lim 1$ expression in the developing appendages of Neanthes versus other bilaterians strengthen the conclusion of Winchell et al. [8] that pattern formation in parapodia evolved independently of that found in arthropod or vertebrate limbs. This suggests that Lhx genes were separately co-opted in these lineages from their apparent symplesiomorphic roles in neural differentiation to autapomorphic roles governing distinctly different aspects of limb outgrowth.

The absence of intricate morphologic and developmental-genetic similarities between annelid and arthropod appendages strongly suggests that these structures arose separately within the protostomes. This is further supported by molecular-phylogenetic findings, as recently published topologies place taxa lacking limbs comparable to parapodia and arthropodia basally within the Lophotrochozoa and Ecdysozoa, respectively (see [8]). While de novo evolution of parapodia and of arthropodia seems likely, two alternative hypotheses merit consideration. The first, predicated on the notion that evolutionarily related structures in disparate phyla may exhibit conflicting patterns of gene expression and morphology due to differential persistence and modification of ancestral conditions $[65,66]$, posits independent divergence of parapodia and arthropodia from a common lateral structure in primitive protostomes. This hypothetical ancestral structure may have served a respiratory role, but was more likely sensory, given the developmental-genetic similarities and functional associations between sensory organs and appendages in modern bilaterians $[65,66]$. A second alternative to de novo evolution is the possibility that parapodia and arthropodia are transformational homologs of pre-existing structures in the separate ancestors of annelids and arthropods. Under this scenario, there is a distinct possibility that the pre-existing structures are still present in modern annelids and arthropods. The precedent for this consideration is the extensive developmental-genetic and morphologic similarity shared between outgrowing chondrichthyan gill arches and vertebrate fin/limb endoskeletons, which suggests that vertebrate paired appendages are transformational homologs of the earlier-evolved gill arches [67]. Paired fins/limbs likely originated in the Silurian (in the now-extinct osteostracan fishes), well after the origin of vertebrates, and their evolution can be further resolved as a process involving co-option of developmental mechanisms from the AP axis [9] and unpaired median fins [68]. Additional insights into the transformational and co- optive processes that spurred the evolution of vertebrate paired appendages may be gleaned from developmentalgenetic comparisons between gnathostomes and their closely related extant outgroups, namely cyclostome fishes and cephalochordates. Unfortunately, no such clarity in modeling appendage evolution from pre-existing structures is immediately available on the protostome side of the tree. Panarthropod appendages (for example, lobopodia and arthropodia), as well as parapodia-bearing polychaetes [69], were already present in the Lower Cambrian, and recent molecular clock estimates date the origin of lophotrochozoans and ecdysozoans to the Lower Ediacaran [70]. The scarcity of fossils from this period makes it difficult to characterize the morphology of ancestral forms of Lophotrochozoa and Ecdysozoa. In addition, bodyplan disparity and lingering uncertainty in the deep phylogenetic relationships within these taxa complicate outgroup comparison.

\section{Apterous, $\lim 1$, and specification of muscle precursors}

In the mesoderm of nascent segments, Nar-ap and Nar-lim1 are each expressed in morphologically undifferentiated and presumably separate groups of cells. Differentiation of these cells over the course of a few segment-additions results in the formation of distinct sets of parapodial muscles. The presumed parapodial levator muscle and posterior members of the dorsal parapodial muscles develop from Nar-ap-positive mesoderm, while neuropodial chaetal sac muscles develop from Nar-lim1positive mesoderm. These complementary expression patterns are reminiscent of the complementary/combinatorial expression of Lhx genes - that is, the 'LIM code' - that controls the differentiation of interneuron and motor neuron subsets in bilaterian nerve cords (for example, [71]). It is, therefore, tempting to speculate that parapodial myoblast diversification requires similar use of a LIM code. Perhaps other Lhx genes are also expressed separately or combinatorially in parapodial muscle precursors.

To our knowledge, this is the first report implicating a lim1 gene in the development of a specific muscle type. apterous, however, is a known 'muscle identity gene' in Drosophila: it specifies precursors of six larval abdominal muscles and the direct flight muscles, and it non-cellautonomously regulates early differentiation of the indirect flight muscles [72,73]. Other $a p$ orthologs may have similar functions. For example, Caenorhabditis ttx-3 is expressed throughout embryonic development in a specific set of head muscles [74], and Apterous protein has been detected in limb muscles of the brine shrimp Artemia franciscana [12]. The activity of $a p$ orthologs in disparate muscles of Neanthes, Drosophila, Caenorhabditis, and Artemia suggests that these genes were independently co-opted for roles in muscle development. Alternatively, their deployment might reflect conservation of a genetic network 
underlying myoblast diversification in protostomes. If true, this network may also involve NK homeobox genes, which show complementary expression in muscle precursors of Drosophila and of Platynereis dumerilii (a nereidid polychaete) [60].

\section{Nar-ap and Nar-lim1 expression in the nervous system}

Precise identification of the neural cells expressing Nar-ap and/or Nar-lim1 awaits thorough characterization of the developing nereidid nervous system, colocalization experiments with other neural markers, and the establishment of a genetic labeling strategy (for example, reporter-based tracing) in annelids that simultaneously reveals neuronal perikarya and projections (see [75]). However, the functions of bilaterian Lhx genes are generally conserved in central nervous systems (see Background), and remarkable developmental-genetic parallels have been demonstrated between the nervous systems of Platynereis and other bilaterians (for example, [76-78]). Thus, known neural functions of $a p$ and lim1 orthologs in model bilaterians serve as a sound platform for postulating the functions of these genes in the Neanthes nervous system.

\section{Nar-ap}

Certain post-mitotic interneurons in Drosophila and Caenorhabditis require ap for proper axonal pathfinding $[33,74]$. Moreover, ap is required in the Drosophila VNC connectives and brain to generate fascicules that contain only axons of ap-expressing interneurons [32,33]. Similarly, in vertebrates, differentiation of a set of post-mitotic spinal cord interneurons requires $L h \times 2 / 9$ for axonal pathfinding and fasciculation into ' $L h \times 2 / 9$-only' bundles $[36,37,40]$. These findings suggest that Nar-ap functions in axonal path finding and fasciculation of brain and VNC interneurons.

Drosophila ap has a second role in post-mitotic interneurons: controlling neuropeptide production. In one interneuron subset of each VNC ganglion, ap regulates FMRF-amide synthesis, and in two other subsets, it regulates expression of peptide biosynthetic enzymes leading to as yet unknown neuropeptides $[34,79]$. In the Drosophila brain, ap is required for the production of leucokinin neuropeptides [35], and certain ap-expressing interneurons innervate the neurosecretory ring gland [33]. These observations suggest that Nar-ap might play a role in neuropeptide synthesis. Consistent with this, the posterior brain of Neanthes shows intense ap expression through the 17-chaetiger stage (the latest stage analyzed; data not shown). Ganglia in this portion of the nereidid brain contain concentrations of neurosecretory cells that show enhanced activity during caudal regeneration and/or later life history stages; they therefore appear to function as hormone-releasing centers, controlling growth and sexual maturation (for example, [80-83]).
Lhx2 functionality in developing vertebrate brains indicates that neural activity of ap orthologs is not limited to post-mitotic neurons. In mouse, for example, Lhx2 plays critical roles in forebrain neurogenesis by specifying fates of the neocortical and hippocampal precursor cells, and by regulating tissue patterning of the pituitary gland [84-86]. Supporting a neurogenesis role for $a p$ in nereidid polychaetes, ap expression in the developing larval brain of Platynereis overlaps significantly with the expression of numerous other genes whose vertebrate orthologs are known to regulate early morphogenesis of the telencephalon [77].

Rincón-Limas et al. [41] inferred conserved expression of ap orthologs in olfactory organs across the Bilateria based on $L h x 2$ expression in epithelia surrounding the embryonic nasal pits of mice and ap expression in the antennae and maxillary palps of flies. In further support of this argument, the differentiation of mouse olfactory neurons requires $L h x 2$ [40], and squid ap mRNAs are present in developing olfactory organs and olfactory lobes of the brain [87]. Polychaete nuchal organs are putatively olfactory, reside partially within the brain, and bear ultrastructural likeness to vertebrate olfactory epithelia $[57,88]$. However, we did not detect Nar-ap expression in the developing nuchal organs of 8-chaetiger juveniles, and we suspect that Nar-ap mRNAs are also absent from younger juveniles' nascent nuchal organs. Although this casts doubt on the hypothetically conserved role of ap orthologs in olfactory differentiation, the identities of Nar-ap-positive cells in other potentially chemosensory organs, that is, the palps and Langdon's organs, remain to be elucidated.

ap orthologs are also active in developing visual systems. The eyes and optic brain lobes of a squid express ap [87], as do the optic lobes of the Drosophila brain [41]. In vertebrates, $L h x 2$ is required for eye morphogenesis [84,89], while both $L h x 2$ and $L h x 9$ are active in the optic tectum/superior colliculus (visual processing centers in the brain) [38,89]. The eyes of Neanthes clearly do not express ap; however, a role in visual system development cannot be rejected, as Narap-positive cells are observed between the posterior eyes (Figures 2Q, T), near the presumed location of the brain's central optic neuropil [83].

\section{Nar-lim 1}

The overall pattern of Nar-lim1 expression in the VNC likely encompasses both motor neurons and interneurons, as these cell types show nerve cord expression of lim1 orthologs in Caenorhabditis [90], Drosophila [43], and vertebrates (for example, [36,44]) (note that for Drosophila and vertebrates, lim1-expressing motor neurons target dorsal musculature). In these model bilaterians, ap and $\lim 1$ orthologs are not co-expressed 
in nerve cord neurons; our Neanthes data are consistent with this pattern, but verification requires doublelabeling experiments. Although the precise function of lim1 in the Drosophila VNC is not known, loss of function and ectopic expression of $\lim 1$ orthologs in Caenorhabditis and vertebrates result in axonal pathfinding and fasciculation defects in nerve cord neurons $[36,44,90]$, indicating similarity of function to ap. The sustained expression of Nar-lim1 during Neanthes VNC development suggests that it controls similar aspects in the final stages of neuronal differentiation.

We observed two general themes of Nar-lim1 expression in the developing juvenile brain. The first is early and persistent expression, particularly in the medial portion of the anterior brain. Here, Nar-lim1-positive cells encompass most of the brain's depth, are traceable from hatchlings through the 13-chaetiger stage (Figures 4A, F, K-M, $\mathrm{R}-\mathrm{T}, \mathrm{X}-\mathrm{Z}$ ), and include a prominent stomatogastric center. Such an early, persistent, and broad expression domain suggests a regulatory role for Nar-lim1 in the initial specification and continued morphogenesis of this brain region. Detailed description of $\lim 1$ expression and function is lacking for the Drosophila brain, but expression of vertebrate lim 1 orthologs is also suggestive of roles in the initial specification and morphogenesis of particular brain regions. In lamprey, for example, expression of the single $\lim 1$ ortholog contributes to early division of the embryonic forebrain and hindbrain into neuromeric segments [91]. In addition, expression of $L h \times 1$ and $L h \times 5$ in embryonic brains of chicken and mouse, respectively, suggests that these genes play roles in controlling early forebrain formation and regionalization [92,93]. Consistent with this, functional analysis of $L h x 5$ in zebrafish embryos demonstrates a role for this gene in promoting forebrain formation by inhibiting the caudalizing effect of Wnt signaling [94].

The second general theme we observed is continuous expression in posterodorsal portions of the brain, but in patterns that are difficult to trace between stages (compare Figures 4J, R, W). Such patterns may be the result of dynamic spatiotemporal expression among relatively stationary sets of cells, or of movement of Nar-lim1-expressing cells. We suspect the latter contributes most significantly to these patterns, as $\lim 1$ orthologs are known to regulate the migration of differentiating neurons in numerous developmental contexts. This occurs in, for example, motor neurons of the lateral motor columns of vertebrate spinal cords $[44,45]$, horizontal cells of the mouse retina [95], Cajal-Retzius cells of the mammalian cerebral cortex [96], precursor cells of the mouse hippocampus [97], presumptive mitral cells of frog olfactory bulbs [39], and interneurons of nematode head ganglia [90].

\section{Conclusions}

A number of observations of gene expression presented in detail here are consistent with conservation of function of Lhx genes in bilaterian neural development and maintenance. Further work is needed to verify the particular identities of Nar-ap and Nar-lim1-expressing neurons. However, based on the strikingly similar activities of ap orthologs, and of lim1 orthologs, in Drosophila and vertebrates (for example, [32,36,43,44]), the observed expression of these genes in Neanthes nerve cord ganglia likely reflects their control over axonal guidance and bundling (along longitudinal tracts) in separate sets of interneurons, and a portion of the observed Nar-lim1 expression in each nerve cord ganglion may well control motor axon targeting to dorsal musculature. Our observations also lead us to infer that Nar-ap may promote neuropeptide synthesis in certain sets of interneurons within the nerve cords and posterior brain, and that Nar$\lim 1$ may contribute to the initial specification and continued morphogenesis of the anterior brain while controlling the migration of differentiating neurons in the posterior brain.

Nar-ap and Nar-lim1 appear to be important for parapodial morphogenesis: Nar-lim1 expression in parapodial ectoderm suggests a patterning role in the ligules, and the non-overlapping expression of both genes in developing segmental mesoderm correlates with the formation of separate parapodial muscles, suggesting that a complementary LIM code underlies the specification of parapodial myoblasts. Our parapodial expression data, lacking specific similarity to the expression patterns (or absence thereof) of $a p$ and lim1 orthologs in developing arthropod or vertebrate appendages, are consistent with a range of scenarios concerning bilaterian appendage evo-devo. One possibility is independent cooption of Lhx gene function in annelid, arthropod, and vertebrate appendage formation from a shared ancestral neural regulatory network. Alternatively, the dissimilar developmental-genetic patterns may reflect independent divergence of annelid, arthropod, and vertebrate appendages from a common ancestral structure: a presumed sensory outgrowth that possibly arose before the cnidarian-bilaterian split $[65,66]$. Although the previous scenarios are in conflict over co-option of Nar-ap and Nar-lim1 in parapodial morphogenesis, our data do seem to indicate less equivocal cases of recruitment of Lhx activity during the evolution of annelid-specific structures; examples include Nar-ap's expression in the jaw sacs and in the presumed Langdon's organs.

\section{Methods}

\section{Gene isolation}

RNA extraction, cDNA synthesis, and PCR (degenerate PCR for initial gene fragments, RACE PCR for additional 
$5^{\prime}$ and $3^{\prime}$ fragments) conformed to protocols described in Winchell et al. [8]. Initial amplification of a 140 base-pair (bp) fragment of the ap homeobox involved the forward primers 5 -acnwsnttyaarcaycaycarct- $3^{\prime}$, which target the sequence coding for TSFKHHQL, and the reverse primers $5^{\prime}$-gcrttytgraaccanacytg-3', which target the sequence coding for QVWFQNA. Initial amplification of a 149 bp fragment of the $\lim 1$ homeobox involved the forward primers $5^{\prime}$-ggnccnmgnacnacnathaargc- $3^{\prime}$, which target the sequence coding for GPRTTIKA, and the reverse primers 5 -ckrttytgraaccanacytgdat-3', which target the sequence coding for IQVWFQNR. Post-PCR purification, cloning, plasmid preparation, sequencing, and assembly of consensus composite sequences followed Winchell et al. [8].

\section{Sequence analysis}

We used BLAST [98] to provisionally assign each composite sequence to a LIM subfamily, and to identify homologous sequences for phylogenetic analyses. The amino acid data set for these analyses, aligned according to Winchell et al. [8], consisted of the LIM1 (approximately 50 amino acids) and LIM2 (approximately 54 amino acids) domains, the linker between them (approximately 12 amino acids), and the homeodomain (approximately 60 amino acids). We used the alignment of Farfán et al. [87] as a guide in delimiting the boundaries of these domains. For optimal tree searches and measurement of nodal support, we used Maximum Likelihood (ML), Bayesian Inference (BI), Maximum Parsimony (MP), and Minimum Evolution (ME) criteria; these were executed according to Winchell et al. [8] except for the following modifications. Using PAUP* [99], starting trees for the MP search were obtained via random stepwise addition with 1,000 replicates, and MP non-parametric bootstrapping included 1,000 replicates with 10 random additions per replicate. For the ML search, we implemented the LG + I + G model (determined by ProtTest [100] to best fit the data) in PhyML [101], and used the best PhyML-calculated ML tree as the starting tree for the ML bootstrap analysis, which included 1,000 replicates. For the BI search, we used the JTT + I + G model, as MrBayes [102] does not accommodate the LG model, and the next best model according to ProtTest was JTT. The search included two independent runs, each for two million generations, sampled every 100. Using the sumt command, we discarded the first 2,001 samples as burnin, combined the remaining trees from each run (36,000 total), and calculated a $50 \%$ majority-rule consensus tree.

\section{Whole-mount in situ hybridization}

We collected, fixed, and stored juvenile $N$. arenaceodentata from a laboratory population using the methods of Winchell et al. [48]. We synthesized sense and antisense digoxigenin-labeled riboprobes by in vitro transcription using SP6 and T7 MEGAscript kits (Life Technologies, Carlsbad, CA, USA) and Dig-11-UTP (Roche Applied Science, Indianapolis, IN, USA). The ap riboprobe, 1,241 bases long, contained 141 bases of $5^{\prime}$ UTR and 1,100 bases of open reading frame, including both LIM boxes and the homeobox. The lim1 riboprobe, 1,002 bases long, contained 204 bases of $5^{\prime}$ UTR and 798 bases of open reading frame, including both LIM boxes. We followed the protocol of Winchell et al. [8] for in situ hybridization, digoxigenin detection, storage of stained juveniles, and their processing for photomicroscopy. However, in regard to the latter, we added a Hoechst 33342 treatment before the glycerol dehydration: worms were incubated for one hour at room temperature with gentle mixing in a $1 \mu \mathrm{M}$ solution of this fluorescent DNA label, which was diluted in pure water plus $0.1 \%$ Tween 20 $\left(\mathrm{H}_{2} \mathrm{OTw}\right)$. After labeling, we washed the worms three times, each time for five minutes, in $\mathrm{H}_{2} \mathrm{OTw}$.

\section{Immunolabeling}

To visualize cilia and neuronal projections, we labeled acetylated $\alpha$-tubulin in 7- and 8-chaetiger juveniles following the strategy of Winchell et al. [48], with a longer Proteinase $\mathrm{K}$ digestion (15 minutes total), and a longer first permeablization/blocking wash (extended to 2 hours). The antibody dilutions remained the same, but the secondary antibody was horseradish peroxidase-conjugated goat anti-mouse IgG (Jackson ImmunoResearch, West Grove, PA, USA). To detect this antibody, we incubated the worms in equal parts $1 \% 3,3^{\prime}$ diaminobenzidine (Sigma-Aldrich, St. Louis, MO, USA), 1\% nickel chloride, and $0.3 \%$ hydrogen peroxide for five minutes at room temperature (these solutions were diluted in pure water). Following the reaction, the worms were washed three times, each time for five minutes in $\mathrm{H}_{2} \mathrm{OTw}$, taken through a methanol gradient (five minutes in each of the following methanol solutions in $\mathrm{H}_{2} \mathrm{OTw}$ : $25 \%, 50 \%, 75 \%, 100 \%$ ), and stored in $100 \%$ methanol at $-20^{\circ} \mathrm{C}$.

\section{Histology, photomicroscopy, and image processing}

We chose uncontorted, intensely stained worms from the in situ hybridization and immunolabeling experiments for transverse sectioning. They were taken from storage, rehydrated into tap water plus $0.1 \%$ Tween 20 (by reversing the above methanol gradient steps), counterstained with Nuclear Fast Red (Vector Laboratories, Burlingame, CA, USA) for 10 minutes at room temperature, and then rinsed for 5 minutes in tap water before dehydration and embedding in Poly/Bed 812-BDMA (Polysciences, Warrington, PA, USA) following the manufacturer's protocol. Sectioning was done on an LKB ultramicrotome at a thickness of $5 \mu \mathrm{M}$ using a Histo diamond knife (Diatome, Hatfield, PA, USA). Sections were mounted under coverslips in Poly-Mount medium (Polysciences, 
Warrington, PA, USA) on Tissue Tack slides (Polysciences, Warrington, PA, USA). Whole-mount specimens and sections were analyzed with a Leica DMR microscope using Nomarski, brightfield, or ultraviolet epifluorescence illumination, and photographed with a Nikon Coolpix 4300 digital camera. Image brightness and contrast were adjusted with Adobe Photoshop, and z-projection images were made with ImageJ. We constructed false-colored images of alkaline phosphatase staining by opening a brightfield micrograph in Photoshop, setting the background color to black, using the Select/Color Range command to choose relevant pixels, and then clearing the inverse selection. We applied the red lookup table to this image in ImageJ (after first converting it to 8-bit grayscale), and then optimized its brightness and contrast. Finally, we merged this image and its corresponding Hoechst 33342-fluorescence image into one image using the Screen layer-blending mode in Photoshop.

\section{Abbreviations}

AAT: Acetylated alpha-tubulin; AP: Anteroposterior; Ba: Bayesian posterior probability; bp: Base pair(s); dpf: Days post-fertilization; Lhx: LIM homeobox; LIM-HD: LIM-homeodomain; ME: Minimum Evolution; ML: Maximum Likelihood; MP: Maximum Parsimony; Nar: Neanthes arenaceodentata; PGZ: Posterior growth zone; RACE: Rapid amplification of cDNA ends; UTR: Untranslated region; VNC: Ventral nerve cord.

\section{Competing interests}

The authors declare that they have no competing interests.

\section{Authors' contributions}

CWW conceived and designed the study with DK, performed all aspects of the research, and wrote the manuscript with help from DKJ. Both authors read and approved the final manuscript.

\section{Acknowledgements}

This work was supported by a grant from the National Aeronautics and Space Administration Astrobiology Program (to DKJ) and research funds from UCLA's graduate program in Ecology and Evolutionary Biology (to (JW). We thank Volker Hartenstein for assistance in sectioning and for sharing laboratory equipment, and two anonymous reviewers for their valuable suggestions.

\section{Author details}

'Department of Ecology and Evolutionary Biology, University of California, Los Angeles, 621 Charles E Young Drive South, Los Angeles CA 90095-1606, USA. ${ }^{2}$ Present address: Department of Molecular and Cell Biology, University of California, Berkeley, 515 LSA \#3200, Berkeley, CA 94720-3200, USA.

Received: 6 June 2012 Accepted: 3 December 2012

Published: 1 February 2013

\section{References}

1. Westheide W: The direction of evolution within the Polychaeta. J Nat Hist 1997, 31:1-15

2. Schmidt-Rhaesa A, Bartolomaeus T, Lemburg C, Ehlers U, Garey JR: The position of the Arthropoda in the phylogenetic system. J Morphol 1998, 238:263-285.

3. Giribet G: Molecules, development and fossils in the study of metazoan evolution; Articulata versus Ecdysozoa revisited. Zoology 2003, 106:303-326.

4. Edgecombe GD, Giribet G, Dunn CW, Hejnol A, Kristensen RM, Neves RC Rouse GW, Worsaae K, Sørensen MV: Higher-level metazoan relationships: recent progress and remaining questions. Org Divers Evol 2011, 11:151-172.
5. Prpic N-M: Parasegmental appendage allocation in annelids and arthropods and the homology of parapodia and arthropodia. Front Zool 2008, 5:17.

6. Jenner RA, Scholtz G: Playing another round of metazoan phylogenetics: historical epistemology, sensitivity analysis, and the position of Arthropoda within the Metazoa on the basis of morphology. In Crustacea and Arthropod Relationships. Edited by Koenemann S, Jenner RA. Boca Raton: CRC Press; 2005:355-386.

7. Dray N, Tessmar-Raible K, Le Gouar M, Vibert L, Christodoulou F, Schipany K, Guillou A, Zantke J, Snyman H, Béhague J, Vervoort M, Arendt D, Balavoine G: Hedgehog signaling regulates segment formation in the annelid Platynereis. Science 2010, 329:339-342.

8. Winchell CJ, Valencia JE, Jacobs DK: Expression of Distal-less, dachshund, and optomotor blind in Neanthes arenaceodentata (Annelida, Nereididae) does not support homology of appendage-forming mechanisms across the Bilateria. Dev Genes Evol 2010, 220:275-295.

9. Shubin N, Tabin C, Carroll S: Fossils, genes, and the evolution of animal limbs. Nature 1997, 388:639-648.

10. Tabin CJ, Carroll SB, Panganiban G: Out on a limb: parallels in vertebrate and invertebrate limb patterning and the origin of appendages. Amer Zool 1999, 39:650-663.

11. Pueyo Jl, Couso JP: Parallels between the proximal-distal development of vertebrate and arthropod appendages: homology without an ancestor? Curr Opin Genet Dev 2005, 15:439-446.

12. Averof $\mathrm{M}$, Cohen $\mathrm{SM}$ : Evolutionary origin of insect wings from ancestral gills. Nature 1997, 385:627-630.

13. Damen WGM, Saridaki T, Averof M: Diverse adaptations of an ancestral gill: a common evolutionary origin for wings, breathing organs, and spinnerets. Curr Biol 2002, 12:1711-1716.

14. Cohen B, Simcox AA, Cohen SM: Allocation of the thoracic imaginal primordia in the Drosophila embryo. Development 1993, 117:597-608

15. Kubota K, Goto S, Eto K, Hayashi S: EGF receptor attenuates Dpp signaling and helps to distinguish the wing and leg cell fates in Drosophila. Development 2000, 127:3769-3776.

16. Diaz-Benjumea FJ, Cohen SM: Interaction between dorsal and ventral cells in the imaginal disc directs wing development in Drosophila. Cell 1993, 75:741-752.

17. Williams JA, Paddock SW, Carroll SB: Pattern formation in a secondary field: a hierarchy of regulatory genes subdivides the developing Drosophila wing disc into discrete subregions. Development 1993, 117:571-584.

18. Blair SS, Brower DL, Thomas JB, Zavortink M: The role of apterous in the control of dorsoventral compartmentalization and PS integrin gene expression in the developing wing of Drosophilia. Development 1994, 120:1805-1815.

19. Ng M, Diaz-Benjumea FJ, Cohen SM: nubbin encodes a POU-domain protein required for proximal-distal patterning in the Drosophila wing. Development 1995, 121:589-599.

20. Pueyo Jl, Galindo MI, Bishop SA, Couso JP: Proximal-distal leg development in Drosophila requires the apterous gene and the Lim1 homologue dlim1. Development 2000, 127:5391-5402.

21. Tsuji T, Sato A, Hiratani I, Taira M, Saigo K, Kojima T: Requirements of Lim1, a Drosophila LIM-homeobox gene, for normal leg and antennal development. Development 2000, 127:4315-4323.

22. Beermann A, Prühs $R$, Lutz $R$, Schröder R: A context-dependent combination of Wnt receptors controls axis elongation and leg development in a short germ insect. Development 2011, 138:2793-2805.

23. Posnien N, Koniszewski NDB, Hein HJ, Bucher G: Candidate gene screen in the red flour beetle Tribolium reveals Six 3 as ancient regulator of anterior median head and central complex development. PLoS Genet 2011, 7:e1002416.

24. Angelini DR, Kikuchi M, Jockusch EL: Genetic patterning in the adult capitate antenna of the beetle Tribolium castaneum. Dev Biol 2009, 327:240-251.

25. Angelini DR, Smith FW, Jockusch EL: Extent with modification: leg patterning in the beetle Tribolium castaneum and the evolution of serial homologs. G3: Genes, Genomes, Genetics 2012, 2:235-247.

26. Abzhanov A, Kaufman TC: Homologs of Drosophila appendage genes in the patterning of arthropod limbs. Dev Biol 2000, 227:673-689.

27. Prpic NM, Tautz D: The expression of the proximodistal axis patterning genes Distal-less and dachshund in the appendages of Glomeris 
marginata (Myriapoda: Diplopoda) suggests a special role of these genes in patterning the head appendages. Dev Biol 2003, 260:97-112.

28. Janssen R, Feitosa NM, Damen WGM, Prpic N-M: The T-box genes H15 and optomotor-blind in the spiders Cupiennius salei, Tegenaria atrica, and Achaeranea tepidariorum and the dorsoventral axis of arthropod appendages. Evol Dev 2008, 10:143-154.

29. Sewell W, Williams T, Cooley J, Terry M, Ho R, Nagy L: Evidence for a nove role for dachshund in patterning the proximal arthropod leg. Dev Genes Evol 2008, 218:293-305.

30. Janssen R, Joakim Eriksson B, Budd GE, Akam M, Prpic N-M: Gene expression patterns in an onychophoran reveal that regionalization predates limb segmentation in pan-arthropods. Evol Dev 2010, 12:363-372.

31. Hobert O, Westphal H: Functions of LIM-homeobox genes. Trends Genet 2000, 16:75-83.

32. Lundgren SE, Callahan CA, Thor S, Thomas JB: Control of neuronal pathway selection by the Drosophila LIM homeodomain gene apterous. Development 1995, 121:1769-1773.

33. Herzig MC, Thor S, Thomas JB, Reichert H, Hirth F: Expression and function of the LIM homeodomain protein Apterous during embryonic brain development of Drosophila. Dev Genes Evol 2001, 211:545-554.

34. Benveniste RJ, Thor S, Thomas JB, Taghert PH: Cell type-specific regulation of the Drosophila FMRF- $\mathrm{NH}_{2}$ neuropeptide gene by Apterous, a LIM homeodomain transcription factor. Development 1998, 125:4757-4765.

35. Herrero P, Magariños M, Torroja L, Canal I: Neurosecretory identity conferred by the apterous gene: lateral horn leucokinin neurons in Drosophila. J Comp Neurol 2003, 457:123-132.

36. Avraham O, Hadas Y, Vald L, Zisman S, Schejter A, Visel A, Klar A Transcriptional control of axonal guidance and sorting in dorsal interneurons by the Lim-HD proteins Lhx9 and Lhx1. Neural Dev 2009, 4:21.

37. Bertuzzi S, Porter FD, Pitts A, Kumar M, Agulnick A, Wassif C, Westphal H: Characterization of $L h x 9$, a novel LIM/homeobox gene expressed by the pioneer neurons in the mouse cerebral cortex. Mech Develop 1999, 80:193-198.

38. Rétaux S, Rogard M, Bach I, Failli V, Besson MJ: Lhx9: A novel LIMhomeodomain gene expressed in the developing forebrain. J Neurosci 1999, 19:783-793.

39. Moreno N, Bachy I, Rétaux S, González A: LIM-homeodomain genes as developmental and adult genetic markers of Xenopus forebrain functional subdivisions. J Comp Neurol 2004, 472:52-72.

40. Hirota J, Mombaerts P: The LIM-homeodomain protein Lhx2 is required for complete development of mouse olfactory sensory neurons. $P$ Natl Acad Sci USA 2004, 101:8751-8755.

41. Rincón-Limas DE, Lu CH, Canal I, Calleja M, Rodríguez-Esteban C, IzpisúaBelmonte JC, Botas J: Conservation of the expression and function of apterous orthologs in Drosophilia and mammals. P Natl Acad Sci USA 1999, 96:2165-2170.

42. Komiyama T, Luo L: Intrinsic control of precise dendritic targeting by an ensemble of transcription factors. Curr Biol 2007, 17:278-285.

43. Lilly B, O'Keefe DD, Thomas JB, Botas J: The LIM homeodomain protein dLim1 defines a subclass of neurons within the embryonic ventral nerve cord of Drosophila. Mech Develop 1999, 88:195-205.

44. Kania A, Jessell TM: Topographic motor projections in the limb imposed by LIM homeodomain protein regulation of ephrin-A:EphA interactions. Neuron 2003, 38:581-596.

45. Palmesino E, Rousso DL, Kao TJ, Klar A, Laufer E, Uemura O, Okamoto H, Novitch BG, Kania A: Foxp1 and Lhx1 coordinate motor neuron migration with axon trajectory choice by gating Reelin signaling. PLOS Biol 2010, 8:e1000446.

46. Zhao Y, Kwan KM, Mailloux CM, Lee WK, Grinberg A, Wurst W, Behringer RR, Westphal H: LIM-homeodomain proteins Lhx1 and Lhx5, and their cofactor Ldb1, control Purkinje cell differentiation in the developing cerebellum. P Natl Acad Sci USA 2007, 104:13182-13186.

47. Pillai A, Mansouri A, Behringer $R$, Westphal $H$, Goulding $M$ : $L h x 1$ and $L h x 5$ maintain the inhibitory-neurotransmitter status of interneurons in the dorsal spinal cord. Development 2007, 134:357-366.

48. Winchell CJ, Valencia JE, Jacobs DK: Confocal analysis of nervous system architecture in direct-developing juveniles of Neanthes arenaceodentata (Annelida, Nereididae). Front Zool 2010, 7:17.
49. Herpin R: Recherches biologiques sur la reproduction et le développement de quelques annélides polychètes. Bull Soc Sci Nat l'Ouest Fr Sér 4 1925, 5:1-250.

50. Reish DJ: The life history of the polychaetous annelid Neanthes caudata (delle Chiaje), including a summary of development in the Family Nereidae. Pac Sci 1957, 11:216-228.

51. Nicoll PA: The anatomy and behavior of the vascular systems in Nereis virens and Nereis limbata. Biol Bull 1954, 106:69-82.

52. Mettam C: Segmental musculature and parapodial movement of Nereis diversicolor and Nephthys hombergi (Annelida: Polychaeta). J Zool-London 1967, 153:245-275.

53. Simmons DK, Pang K, Martindale MQ: LIM homeobox genes in the ctenophore Mnemiopsos leidyi: the evolution of neural cell type specification. EvoDevo 2012, 3:2.

54. Srivastava M, Larroux C, Lu DR, Mohanty K, Chapman J, Degnan BM, Rokhsar DS: Early evolution of the LIM homeobox gene family. BMC Biol 2010, 8:4

55. Langdon FE: The sense-organs of Nereis virens Sars. J Comp Neurol 1900, $10: 1-77$

56. Gilpin-Brown JB: The development and structure of the cephalic nerves in Nereis. J Comp Neurol 1958, 109:317-348.

57. Purschke G: Ultrastructure of nuchal organs in polychaetes (Annelida) - new results and review. Acta Zool-Stockholm 1997, 78:123-143.

58. Prud'homme B, de Rosa R, Arendt D, Julien J-F, Pajaziti R, Dorresteijn AWC, Adoutte A, Wittbrodt J, Balavoine G: Arthropod-like expression patterns of engrailed and wingless in the annelid Platynereis dumerilii suggest a role in segment formation. Curr Biol 2003, 13:1876-1881.

59. de Rosa R, Prud'homme B, Balavoine G: caudal and even-skipped in the annelid Platynereis dumerilii and the ancestry of posterior growth. Evol Dev 2005, 7:574-587

60. Saudemont A, Dray N, Hudry B, Le Gouar M, Vervoort M, Balavoine G: Complementary striped expression patterns of NK homeobox genes during segment formation in the annelid Platynereis. Dev Biol 2008, 317:430-443.

61. Smith JE: The nervous anatomy of the body segments of nereid polychaetes. Philos T Roy Soc B 1957, 240:135-196.

62. Arendt D, Tessmar-Raible K, Snyman H, Dorresteijn AW, Wittbrodt J: Ciliary photoreceptors with a vertebrate-type opsin in an invertebrate brain. Science 2004, 306:869-871.

63. Rodriguez-Esteban C, Schwabe JWR, De La Peña J, Rincon-Limas DE, Magallón J, Botas J, Izpisúa-Belmonte JC: Lhx2, a vertebrate homologue of apterous, regulates vertebrate limb outgrowth. Development 1998, 125:3925-3934.

64. Tzchori I, Day TF, Carolan PJ, Zhao Y, Wassif CA, Li L, Lewandoski M, Gorivodsky M, Love PE, Porter FD, Westphal H, Yang Y: LIM homeobox transcription factors integrate signaling events that control three-dimensional limb patterning and growth. Development 2009, 136:1375-1385.

65. Jacobs DK, Nakanishi N, Yuan D, Camara A, Nichols SA, Hartenstein V: Evolution of sensory structures in basal Metazoa. Integr Comp Biol 2007, 47:712-723.

66. Jacobs DK, Gold DA, Nakanishi N, Yuan D, Camara A, Nichols SA, Hartenstein $V$, Schierwater B, DeSalle R: Basal metazoan sensory evolution. In Key Transitions in Animal Evolution. Edited by Enfield, NH: Science Publishers \& CRC Press; 2010:175-193.

67. Gillis JA, Dahn RD, Shubin NH: Shared developmental mechanisms pattern the vertebrate gill arch and paired fin skeletons. Proc Natl Acad SCi USA 2009, 106:5720-5724.

68. Johanson Z: Evolution of paired fins and the lateral somitic frontier. J Exp Zool (Mol Dev Evol) 2010, 314B:347-352.

69. Conway Morris S, Peel JS: The earliest annelids: lower Cambrian polychaetes from the Sirius Passet Lagerstätte, Peary land, North Greenland. Acta Palaeontol Pol 2008, 53:137-148.

70. Erwin DH, Laflamme M, Tweedt SM, Sperling EA, Pisani D, Peterson KJ: The Cambrian conundrum: early divergence and later ecological success in the early history of animals. Science 2011, 334:1091-1097.

71. Thor S, Andersson SGE, Tomlinson A, Thomas JB: A LIM-homeodomain combinatorial code for motor-neuron pathway selection. Nature 1999, 397:76-80.

72. Bourgouin C, Lundgren SE, Thomas JB: apterous is a Drosophila LIM domain gene required for the development of a subset of embryonic muscles. Neuron 1992, 9:549-561. 
73. Ghazi A, Anant S, VijayRaghavan K: Apterous mediates development of direct flight muscles autonomously and indirect flight muscles through epidermal cues. Development 2000, 127:5309-5318.

74. Hobert O, Mori I, Yamashita Y, Honda H, Ohshima Y, Liu Y, Ruvkun G: Regulation of interneuron function in the C. elegans thermoregulatory pathway by the $t t x-3$ LIM homeobox gene. Neuron 1997, 19:345-357.

75. Callahan CA, Yoshikawa S, Thomas JB: Tracing axons. Curr Opin Neurobiol 1998, 8:582-586.

76. Denes AS, Jékely $G$, Steinmetz PRH, Raible F, Snyman $H$, Prud'homme B, Ferrier DEK, Balavoine G, Arendt D: Molecular architecture of annelid nerve cord supports common origin of nervous system centralization in Bilateria. Cell 2007, 129:277-288.

77. Tomer R, Denes AS, Tessmar-Raible K, Arendt D: Profiling by image registration reveals common origin of annelid mushroom bodies and vertebrate pallium. Cell 2010, 142:800-809.

78. Demilly A, Simionato E, Ohayon D, Kerner P, Garcès A, Vervoort M: Coe genes are expressed in differentiating neurons in the central nervous system of protostomes. PLoS One 2011, 6:e21213.

79. Allan DW, Park D, St. Pierre SE, Taghert PH, Thor S: Regulators acting in combinatorial codes also act independently in single differentiating neurons. Neuron 2005, 45:689-700.

80. Golding DW, Whittle AC: Neurosecretion and related phenomena in annelids. Int Rev Cytol 1977, Suppl 5:189-302

81. Bell K, Marsden JR: Age-related histological changes in neurosecretory cells in the supraesophageal ganglion of Nereis virens (Annelida, Polychaeta). Can J Zool 1980, 58:1735-1740.

82. Dhainaut-Courtois N, Dubois MP, Tramu G, Masson M: Occurrence and coexistence in Nereis diversicolor O F Müller (Annelida Polychaeta) of substances immunologically related to vertebrate neuropeptides. Cell Tissue Res 1985, 242:97-108.

83. Heuer CM, Loesel R: Immunofluorescence analysis of the internal brain anatomy of Nereis diversicolor (Polychaeta, Annelida). Cell Tissue Res 2008, 331:713-724.

84. Porter FD, Drago J, Xu Y, Cheema SS, Wassif C, Huang SP, Lee E, Grinberg A, Massalas JS, Bodine D, Alt F, Westphal H: Lhx2, a LIM homeobox gene, is required for eye, forebrain, and definitive erythrocyte development. Development 1997, 124:2935-2944.

85. Mangale VS, Hirokawa KE, Satyaki PRV, Gokulchandran N, Chikbire S, Subramanian L, Shetty AS, Martynoga B, Paul J, Mai MV, Li Y, Flanagan LA, Tole S, Monuki ES: Lhx2 selector activity specifies cortical identity and suppresses hippocampal organizer fate. Science 2008, 319:304-309.

86. Zhao $Y$, Mailloux CM, Hermesz E, Palkóvits $M$, Westphal H: A role of the LIM-homeobox gene $L h \times 2$ in the regulation of pituitary development. Dev Biol 2010, 337:313-323.

87. Farfán C, Shigeno S, Nödl M-T, de Couet HG: Developmental expression of apterous/Lhx2/9 in the sepiolid squid Euprymna scolopes supports an ancestral role in neural development. Evol Dev 2009, 11:354-362.

88. Whittle AC, Zahid ZR: Fine structure of nuchal organs in some errant polychaetous annelids. J Morphol 1974, 144:167-184.

89. Seth A, Culverwell J, Walkowicz M, Toro S, Rick JM, Neuhauss SCF, Varga ZM, Karlstrom RO: belladonna/(Ihx2) is required for neural patterning and midline axon guidance in the zebrafish forebrain. Development 2006, 133:725-735.

90. Hobert O, D'Alberti T, Liu Y, Ruvkun G: Control of neural development and function in a thermoregulatory network by the LIM homeobox gene lin11. J Neurosci 1998, 18:2084-2096.

91. Osorio J, Mazan S, Rétaux S: Organisation of the lamprey (Lampetra fluviatilis) embryonic brain: insights from LIM-homeodomain, Pax and hedgehog genes. Dev Biol 2005, 288:100-112.

92. Sheng HZ, Bertuzzi S, Chiang C, Shawlot W, Taira M, Dawid I, Westphal H: Expression of murine $L h \times 5$ suggests a role in specifying the forebrain. Dev Dynam 1997, 208:266-277.

93. Sun X, Saitsu H, Shiota K, Ishibashi M: Expression dynamics of the LIMhomeobox genes, $L h x 1$ and $L h x 9$, in the diencephalon during chick development. Int J Dev Biol 2008, 52:33-41.

94. Peng G, Westerfield M: Lhx5 promotes forebrain development and activates transcription of secreted Wnt antagonists. Development 2006, 133:3191-3200.

95. Poché RA, Ming Kwan K, Raven MA, Furuta Y, Reese BE, Behringer RB: Lim1 is essential for the correct laminar positioning of retinal horizontal cells. J Neurosci 2007, 27:14099-14107.
96. Abellan A, Menuet A, Dehay C, Medina L, Rétaux S: Differential expression of LIM-homeodomain factors in Cajal-Retzius cells of primates, rodents, and birds. Cereb Cortex 2010, 20:1788-1798.

97. Zhao $Y$, Sheng HZ, Amini R, Grinberg A, Lee E, Huang S, Taira M, Westphal $\mathrm{H}$ : Control of hippocampal morphogenesis and neuronal differentiation by the LIM homeobox gene Lhx5. Science 1999, 284:1155-1158.

98. Altschul SF, Madden TL, Schäffer AA, Zhang J, Zhang Z, Miller W, Lipman DJ: Gapped BLAST and PSI-BLAST: a new generation of protein database search programs. Nucleic Acids Res 1997, 25:3389-3402.

99. Swofford DL, PAUP*: Phylogenetic Analysis Using Parsimony (* and Other Methods). Version 4.0 b10. Sunderland: Sinauer Associates; 2003.

100. Abascal R, Zardoya R, Posada D: ProtTest: selection of best-fit models of protein evolution. Bioinformatics 2005, 21:2104-2105.

101. Guindon S, Gascuel O: A simple, fast, and accurate algorithm to estimate large phylogenies by maximum likelihood. Syst Biol 2003, 52:696-704.

102. Ronquist F, Huelsenbeck JP: MRBAYES 3: Bayesian phylogenetic inference under mixed models. Bioinformatics 2003, 19:1572-1574.

doi:10.1186/2041-9139-4-4

Cite this article as: Winchell and Jacobs: Expression of the Lhx genes apterous and $\lim 1$ in an errant polychaete: implications for bilaterian appendage evolution, neural development, and muscle diversification. EvoDevo 2013 4:4.

\section{Submit your next manuscript to BioMed Central and take full advantage of:}

- Convenient online submission

- Thorough peer review

- No space constraints or color figure charges

- Immediate publication on acceptance

- Inclusion in PubMed, CAS, Scopus and Google Scholar

- Research which is freely available for redistribution

Submit your manuscript at www.biomedcentral.com/submit
C) Biomed Central 